Board of Governors of the Federal Reserve System

International Finance Discussion Papers

Number 1082

June 2013

\title{
Collateral Constraints and Macroeconomic Asymmetries
}

\author{
Luca Guerrieri \\ and \\ Matteo Iacoviello
}

NOTE: International Finance Discussion Papers are preliminary materials circulated to stimulate discussion and critical comment. References to International Finance Discussion Papers (other than an acknowledgment that the writer has had access to unpublished material) should be cleared with the author or authors. Recent IFDPs are available on the Web at www.federalreserve.gov/pubs/ifdp/. This paper can be downloaded without charge from the Social Science Research Network electronic library at www.ssrn.com. 


\title{
Collateral Constraints and Macroeconomic Asymmetries*
}

\author{
Luca Guerrieri ${ }^{\dagger}$ \\ Federal Reserve Board \\ Matteo Iacoviello \\ Federal Reserve Board
}

June 11, 2013

\begin{abstract}
A model with collateral constraints displays asymmetric responses to house price changes. When housing wealth is high, collateral constraints become slack, and the response of consumption and hours to shocks that move house prices is positive yet small. When housing wealth is low, collateral constraints become tight, and the response of consumption and hours to house price changes is negative and large. This finding is corroborated using evidence from national, state-level, and MSA-level data. Wealth effects computed in normal times may underestimate the response to large house price declines. Debt-relief policies may be far more effective during protracted housing slumps.
\end{abstract}

KEYWORDS: Housing, Collateral Constraints, Occasionally Binding Constraints, Household Leverage.

JEL CLASSIFICATION: E32, E44, E47, R21, R31

\footnotetext{
${ }^{*}$ The views expressed in this paper are solely the responsibility of the authors and should not be interpreted as reflecting the views of the Board of Governors of the Federal Reserve System or of any other person associated with the Federal Reserve System. Replication codes that implement our solution technique for DSGE models with occasionally binding constraints using an add-on to Dynare are available upon request. Stedman Hood and Walker Ray performed superb research assistance.

${ }^{\dagger}$ Luca Guerrieri, Office of Financial Stability, Federal Reserve Board, 20th and C St. NW, Washington, DC 20551. Email: luca.guerrieri@frb.gov.

${ }^{\ddagger}$ Matteo Iacoviello, Division of International Finance, Federal Reserve Board, 20th and C St. NW, Washington, DC 20551. Email: matteo.iacoviello@frb.gov.
} 


\section{Introduction}

Accounts of the recent financial crisis attribute a central role to the collapse in housing wealth and to financial frictions in explaining the sharp contraction in consumption and overall economic activity. ${ }^{1}$ Prior to the crisis, however, the rise in housing wealth associated with the steady increase in house prices between 2001 and 2006 seems to have had much less effect in boosting consumption. Taken together, these observations point to an asymmetry in the relationship between house prices and economic activity. In this paper, we argue that the sensitivity of macroeconomic aggregates to movements in housing prices can be large when housing wealth is low, and small when housing wealth is high. We develop this argument in a quantitative general equilibrium model, and confirm its predictions against U.S. data.

In the model, when housing wealth is high, collateral constraints are slack, and the sensitivity of borrowing and spending to changes in house prices is positive but not large. Conversely, when housing wealth is low, collateral constraints are tight, and borrowing and expenditures move with house prices in a more dramatic fashion. As a consequence, the effects of movements in house prices are larger and more severe when housing wealth is low than when it is high. The empirical analysis supports our model's implications that the fallout from a persistent decline in house prices is much more severe than the boost to activity from an increase.

The model used in this paper is borrowed from Iacoviello and Neri (2010). It is an estimated DSGE model that allows for numerous empirically-realistic nominal and real rigidities. In addition, the model encompasses a housing sector. On the supply side, a separate sector produces new homes using capital, labor, and land. On the demand side, households consume housing services and can use housing as collateral for loans. In characterizing the properties of the model, we focus on a shock to households preferences for housing. When house prices decline, household wealth is reduced, collateral constraints become binding, and the effective share of credit-constrained households increases. In contrast, house price increases relax households' borrowing constraints. We employ a non-linear solution technique that allows us to capture asymmetric effects of shocks depending on whether the shocks push housing wealth up or down. ${ }^{2}$ An empirical validation exercise, based on matching moments, indicates that the model fits the data when the response of consumption and hours to shocks that move house prices is much larger when house prices are low than when they are high.

Figure 1 offers a first look at national house prices. It shows the evolution of U.S. house

\footnotetext{
${ }^{1}$ For instance, see Mian and Sufi (2010) and Hall (2011).

${ }^{2}$ Iacoviello and Neri (2010) solve a model of this kind using a first-order perturbation method. As a result, the importance of credit-constrained agents remains constant and the effects of shocks that move house prices are symmetric for increases and decreases.
} 
prices over the period 1976-2011. The top panel superimposes the time series of U.S. house prices and of U.S. aggregation consumption expenditures. The correlation coefficient is 0.55 , a substantial but not extreme level. The bottom panel is a scatterplot of changes in consumption and changes in house prices. It highlights that most of the positive correlation seems to be driven by periods when house prices are below average, both during the 1992-1993 period, and during the 2007-2009 recession. When periods with house price decreases are included, there is a strong positive correlation between consumption and house prices. However, excluding periods with declines in house prices results in almost no correlation between consumption and house prices.

We test the prediction of the model that house price changes should have asymmetric effects using both national and regional data. We proceed in two steps. First, we estimate a VAR that includes U.S. consumption and house prices. Each equation in the VAR allows for separate house price terms, depending on whether house prices are high or low. Estimates of the VAR parameters based on data generated by the model imply a strong asymmetry in the response of consumption to innovations in house prices, depending on whether the shock to house prices is positive or negative. These population estimates are remarkably consistent with estimates obtained using aggregate U.S. data.

In the second step, we use regional data. The task of isolating the asymmetric effect of changes in house prices using only national data may be fraught with difficulty. Barring the Great Recession, house price declines have been rare at the national level. In addition, knowing what would have happened to economic activity had house prices not changed raises challenging identification issues. Accordingly, we use panel and cross-sectional regressions at the regional level. Regional data exhibit greater variation in house prices. Moreover, at the regional level, we can use instruments that other studies have found useful in isolating exogenous changes in house prices. In doing so, we verify that the asymmetries uncovered using national aggregate data are even more pronounced when using regional data. ${ }^{3}$

Our analysis builds on an expanding literature that has linked changes in measures of economic activity, such as consumption and employment, to changes in house prices. Recent contributions include Case, Quigley, and Shiller (2005), Campbell and Cocco (2007), Mian and Sufi (2011), Midrigan and Philippon (2011), Mian, Rao, and Sufi (2012), Liu, Wang, and Zha (2013), and Abdallah and Lastrapes (2012). This literature points towards an important

\footnotetext{
${ }^{3}$ We are keenly aware that house prices are endogenous both in theory and in the data. Our modeling strategy attributes most of the variation in house prices to shocks to housing preferences, as in recent work by Liu, Wang, and Zha (2013). Part of our empirical analysis looks for instruments for house price changes as a way to isolate housing preference shocks from other shocks that are more likely to jointly move both housing and other endogenous variables, as done by Mian and Sufi (2011).
} 
role for housing as collateral in influencing both consumption and employment. However, this literature has not recognized that such a channel implies asymmetric relationships for house price increases and declines with other measures of aggregate activity. Our uncovering of statistically significant differences for house price increases and declines, as theory predicts, provides more cogent support for the hypothesis that the housing collateral channel has played an important role in linking house price fluctuations to other key measures of economic activity. In addition, an important contribution of this paper is that we analyze this asymmetry not only empirically, but also theoretically in the context of a quantitative equilibrium model that is suitable for policy analysis. ${ }^{4}$

To the best of our knowledge, Case, Quigley, and Shiller (2005) and Case, Quigley, and Shiller (2011) first highlighted the possibility, using U.S. state-level data, that house prices could have asymmetric effects on consumption. Their 2011 paper, in particular, finds in some specifications that declines in housing market wealth have had negative and somewhat larger effects upon consumption than previous increases. Our analysis extends their work by considering a larger set of variables and regional detail, by tying the results to a full-blown estimated equilibrium model, and by illustrating the policy relevance of this asymmetry. ${ }^{5}$

Section 2 presents a basic, partial-equilibrium model that illustrates how collateral constraints may imply an asymmetry in the relationship between house prices and consumption. Section 3 considers an empirically-validated general equilibrium model. Section 4 highlights the properties of the general equilibrium model and matches them against an asymmetric VAR estimated on aggregate U.S. data. Section 5 presents additional evidence on asymmetries in the relationship between house prices and other measures of economic activity based on state and MSA-level data. Section 6 considers an experiment which highlights how the same policy a transfer to indebted borrowers - can have opposite effects depending on whether house prices are high or low. Section 7 concludes.

\section{The Basic Model: Collateral Constraints and Asymmetries}

To fix ideas regarding the fundamental asymmetry introduced by collateral constraints, it is useful to work through a basic model and analyze its implications for how consumption responds to

\footnotetext{
4 The idea that borrowing constraints may introduce asymmetric responses of consumption to shocks is a well-known result in macroeconomics. For instance, Jappelli and Pistaferri (2010) observe that if households are credit constrained, they will cut consumption strongly when hit by a negative transitory shock but will not react much to a positive one.

${ }^{5}$ Our paper is also related to the work of Lustig and van Nieuwerburgh (2010), who find that in times when US housing collateral is scarce nationally, regional consumption is about twice as sensitive to income shocks. However, the channel they emphasize - time variation in risk-sharing among regions - is different from ours.
} 
changes in house prices. Throughout this section, we sidestep obvious general equilibrium considerations and assume that the price of housing is exogenous. We relax all these assumptions in the full DSGE model of the next section.

Consider the problem of a household that has to choose profiles for goods consumption $c_{t}$, housing $h_{t}$, and borrowing $b_{t}$. The household's problem is to maximize

$$
E_{0} \sum_{t=0}^{\infty} \beta^{t}\left(\log c_{t}+\mathrm{j} \log h_{t}\right)
$$

where $E_{0}$ is the conditional expectation operator. The household is subject to the following constraints:

$$
\begin{aligned}
c_{t}+q_{t} h_{t} & =y+b_{t}-R b_{t-1}+q_{t}\left(1-\delta_{h}\right) h_{t-1} \\
b_{t} & \leq \mathrm{m} q_{t} h_{t} \\
\log q_{t} & =\rho_{q} \log q_{t-1}+\varepsilon_{q, t} .
\end{aligned}
$$

The first constraint is the budget constraint. Income $y$ is fixed and normalized to one. The term $b_{t}$ denotes one-period debt. The gross one-period interest rate is $R$. Housing, which depreciates at rate $\delta_{h}$, has a price $q_{t}$ in unit of consumption. The second constraint is a borrowing constraint that limits borrowing to a maximum fraction $\mathrm{m}$ of housing wealth. The third equation describes the price of housing, $q_{t}$, which follows an $\mathrm{AR}(1)$ stochastic process, where $\varepsilon_{q}$ is a zero-mean, i.i.d. process with variance $\sigma_{q}^{2}$.

Denoting with $\lambda_{t}$ the Lagrange multiplier on the borrowing constraint, the Euler equation for consumption is given by:

$$
\frac{1}{c_{t}}=\beta R E_{t}\left(\frac{1}{c_{t+1}}\right)+\lambda_{t} .
$$

To develop the intuition for our result, it is useful to consider a log-linear approximation of equation (5) in a steady state without shocks. Under the assumption that $\beta R<1$, the borrowing constraint binds and leverage (the ratio of debt to housing wealth) is at its upper bound given by the maximum loan-to-value ratio $(\mathrm{LTV}) \mathrm{m}$. In that steady state, $\bar{\lambda}>0$, and $\bar{c}=$ $\bar{y}-\left((R-1) \mathrm{m}-\delta_{h}\right) \bar{q} \bar{h}$. Solving this equation forward and linearizing, one obtains the following expression for consumption in percent deviation from steady state, $\widehat{c}_{t}$ :

$$
\widehat{c}_{t}=-\frac{1-\beta R}{\bar{\lambda}} E_{t}\left(\lambda_{t}-\bar{\lambda}+\beta R\left(\lambda_{t+1}-\bar{\lambda}\right)+\beta^{2} R^{2}\left(\lambda_{t+2}-\bar{\lambda}\right)+\ldots\right)
$$

Expressing the Euler equation as above shows that consumption depends negatively on current 
and future expected borrowing constraints. As shown by equation (3), increases in $q_{t}$ will loosen the borrowing constraint. So long as they keep $\lambda_{t}$ positive, increases and decreases in $q_{t}$ will have roughly symmetric effects on $c_{t}$. However, large enough increases in $q_{t}$ lead to a fundamental asymmetry. The multiplier $\lambda_{t}$ cannot fall below zero. Consequently, large increases in $q_{t}$ can bring $\lambda_{t}$ to its lower bound and will have proportionally smaller effects on $c_{t}$ than decreases in $q_{t}$. Intuitively, an impatient borrower prefers a consumption profile that is declining over time. A large, temporary increase in house prices will enable such a profile (high $c$ today, low $c$ tomorrow) without borrowing all the way up to the limit.

More formally, the household's state at time $t$ is its housing $h_{t-1}$, debt $b_{t-1}$ and the current realization of the house price $q_{t}$, and the optimal decision are given by the consumption choice $c_{t}=\mathcal{C}\left(q_{t}, h_{t-1}, b_{t-1}\right)$, the housing choice $h_{t}=\mathcal{H}\left(q_{t}, h_{t-1}, b_{t-1}\right)$ and the debt choice $b_{t}=\mathcal{B}\left(q_{t}, h_{t-1}, b_{t-1}\right)$ that maximize expected utility subject to (2) and (3), given the house price process. Figure 2 shows the optimal leverage and the consumption function obtained from the model outlined above. ${ }^{6}$ As the figure illustrates, high house prices are associated with slack borrowing constraints, and with a lower sensitivity of consumption to changes in house prices. Instead, when household borrowing is constrained - an outcome that is more likely when house prices are low and the initial stock of debt is high - the sensitivity of consumption to changes in house prices becomes large. This idea is developed further both in the full model and in the empirical analysis to follow.

\section{The Full Model: Demand Effects in General Equilibrium}

To quantify the importance of the asymmetric relationship between house prices and consumption, we embed the basic ideas of Section 2 in an empirically validated general equilibrium model. The model is borrowed from Iacoviello and Neri (2010). It builds on Christiano, Eichenbaum, and Evans (2005) and Smets and Wouters (2007) by allowing for two sectors, a housing sector and non-housing a sector, as well as financial frictions and borrowing collateralized by housing following Iacoviello (2005).

On the supply side, firms in the housing sector produce new homes using capital, labor and land. Firms in the non-housing sector produce intermediate consumption and investment goods

\footnotetext{
${ }^{6}$ The policy functions depicted in Figure 2 are obtained from standard global solution methods (value function iteration). The calibration matches the parameter values in Table 1 . Namely, $\beta=0.988, \mathrm{j}=0.12, \mathrm{~m}=0.925$, $R=1.01, \delta=0.01$. The resulting steady-state housing wealth to quarterly income ratio is 6.1 , close to the housing wealth to income ratio for impatient households in the steady state of the full model presented below. For the house price process we set $\rho_{q}=0.96$ and $\sigma_{q}=0.0175$, in order to match a standard deviation of the quarterly growth rate of house prices equal to 1.77 percent, as in the data.
} 
using capital and labor. The non-housing sector features nominal price rigidities. Both sectors have nominal wage rigidities and real rigidities in the form of imperfect labor mobility, capital adjustment costs and variable capital utilization.

On the household side, there is a continuum of agents in each of two groups with different discount factors. Households with the higher discount factor are dubbed "patient," the other "impatient." Patient households accumulate housing and own the productive capital of the economy. They make consumption and investment decisions and supply labor to firms and funds to both firms and impatient households. Impatient households work, consume, and accumulate housing. Their higher impatience pushes them to borrow.

In the non-stochastic steady state, the housing collateral constraint is binding for the impatient households; however, shocks that lead to a rise in the value of the collateral can make the constraint temporarily slack, thus weakening the effect of changes in house prices on economic activity. To quantify the importance of this mechanism, we focus on two shocks: a shock to housing preferences; and a shock to the maximum LTV ratio, that we label a "credit shock". We single out housing preference shocks following Liu, Wang, and Zha (2013) and Iacoviello and Neri (2010), who show, using estimated dynamic equilibrium models, that such shocks can explain a substantial fraction of fluctuations in house prices. ${ }^{7}$ We allow for credit shocks because they can proxy for a variety of factors, not necessarily related to movements in the price of collateral, that affect the ability of agents to borrow and spend, as in work by Jermann and Quadrini (2012), Guerrieri and Lorenzoni (2011) and Favara and Imbs (2010). ${ }^{8}$

Below, we sketch the key features of the model. Appendix A provides additional details as well as the list of all necessary conditions for an equilibrium.

\subsection{Households}

Within each group of patient and impatient households, a representative household maximizes:

$$
E_{0} \sum_{t=0}^{\infty}\left(\beta G_{C}\right)^{t}\left(\Gamma_{c} \log \left(c_{t}-\varepsilon c_{t-1}\right)+\mathrm{j}_{t} \log h_{t}-\frac{\tau}{1+\eta}\left(n_{c, t}^{1+\xi}+n_{h, t}^{1+\xi}\right)^{\frac{1+\eta}{1+\xi}}\right)
$$

\footnotetext{
7 The notion that housing and other asset prices are not easily explained by changes in other macroeconomic variables has a long tradition in macroeconomics: see for instance the work by Shiller (2000). Soo (2013) develops measures of sentiment across local housing markets by quantifying the positive and negative tone of housing news in local newspaper articles, and finds that the housing sentiment can predict over 70 percent of the variation in aggregate house price growth.

${ }^{8}$ As a robustness check, we substituted the credit shock with other shocks (such as shocks to technology or labor supply), with little change in our qualitative and quantitative results.
} 


$$
E_{0} \sum_{t=0}^{\infty}\left(\beta^{\prime} G_{C}\right)^{t}\left(\Gamma_{c}^{\prime} \log \left(c_{t}^{\prime}-\varepsilon^{\prime} c_{t-1}^{\prime}\right)+\mathrm{j}_{t} \log h_{t}^{\prime}-\frac{\tau}{1+\eta^{\prime}}\left(\left(n_{c, t}^{\prime}\right)^{1+\xi^{\prime}}+\left(n_{h, t}^{\prime}\right)^{1+\xi^{\prime}}\right)^{\frac{1+\eta^{\prime}}{1+\xi^{\prime}}}\right) .
$$

Variables accompanied by the prime symbol refer to patient households. The terms $c, h, n_{c}$, $n_{h}$ are consumption, housing, hours in the consumption sector and hours in the housing sector. The discount factors are $\beta$ and $\beta^{\prime}$. By definition, $\beta^{\prime}<\beta$. The term $\mathrm{j}_{t}$ captures shocks to housing preferences. The shock follows:

$$
\log \mathbf{j}_{t}=\left(1-\rho_{j}\right) \log \overline{\mathbf{j}}+\rho_{j} \log \mathbf{j}_{t-1}+u_{j, t},
$$

where $u_{j, t}$ is an i.i.d. process with variance $\sigma_{j}^{2}$. Above, $\varepsilon$ measures habits in consumption and $G_{C}$ is the growth rate of consumption along the balanced growth path. The scaling factors $\Gamma_{c}=\left(G_{C}-\varepsilon\right) /\left(G_{C}-\beta \varepsilon G_{C}\right)$ and $\Gamma_{c}^{\prime}=\left(G_{C}-\varepsilon^{\prime}\right) /\left(G_{C}-\beta^{\prime} \varepsilon^{\prime} G_{C}\right)$ ensure that the marginal utilities of consumption are $1 / c$ and $1 / c^{\prime}$ in the non-stochastic steady state. The specification of the disutility of labor $(\xi, \eta \geq 0)$ allows for less than perfect labor mobility across sectors. Positive values of $\xi$ and $\xi^{\prime}$ imply that relative hours respond relatively less to sectoral wage differentials.

Patient households maximize their utility subject to:

$$
\begin{gathered}
c_{t}+\frac{k_{c, t}}{\mathrm{~A}_{k, t}}+k_{h, t}+k_{b, t}+q_{t} h_{t}+p_{l, t} l_{t}-b_{t}=\frac{w_{c, t} n_{c, t}}{X_{w c, t}}+\frac{w_{h, t} n_{h, t}}{X_{w h, t}} \\
+\left(R_{c, t} z_{c, t}+\frac{1-\delta_{k c}}{\mathrm{~A}_{k, t}}\right) k_{c, t-1}+\left(R_{h, t} z_{h, t}+1-\delta_{k h}\right) k_{h, t-1}+p_{b, t} k_{b, t}-\frac{R_{t-1} b_{t-1}}{\pi_{t}} \\
+\left(p_{l, t}+R_{l, t}\right) l_{t-1}+q_{t}\left(1-\delta_{h}\right) h_{t-1}+D i v_{t}-\phi_{t}-\frac{a\left(z_{c, t}\right) k_{c, t-1}}{\mathrm{~A}_{k, t}}-a\left(z_{h, t}\right) k_{h, t-1} .
\end{gathered}
$$

Patient agents choose consumption $c_{t}$, capital in the consumption sector $k_{c, t}$, capital $k_{h, t}$ and intermediate inputs $k_{b, t}$ (priced at $p_{b, t}$ ) in the housing sector, housing $h_{t}$ (priced at $q_{t}$ ), land $l_{t}$ (priced at $p_{l, t}$ ), hours $n_{c, t}$ and $n_{h, t}$, capital utilization rates $z_{c, t}$ and $z_{h, t}$, and borrowing $b_{t}$ (loans if $b_{t}$ is negative) to maximize utility subject to (10). The term $\mathrm{A}_{k, t}$ is the trend in investment-specific technology, which represents the marginal cost of producing capital used in the non-housing sector. Loans are set in nominal terms and yield a riskless nominal return of $R_{t}$. Real wages are denoted by $w_{c, t}$ and $w_{h, t}$, real rental rates by $R_{c, t}$ and $R_{h, t}$, depreciation rates by $\delta_{k c}$ and $\delta_{k h}$. The terms $X_{w c, t}$ and $X_{w h, t}$ denote the markup (due to monopolistic competition in the labor market) between the wage paid by the wholesale firm and the wage paid to the households, which accrues to the labor unions (the details of nominal rigidities in the labor market are in Appendix A). Finally, $\pi_{t}=P_{t} / P_{t-1}$ is the money inflation rate in the 
consumption sector, Div $v_{t}$ are lump-sum profits from final good firms and from labor unions, $\phi_{t}$ denotes convex adjustment costs for capital, $z$ is the capital utilization rate that transforms physical capital $k$ into effective capital $z k$ and $a(\cdot)$ is the convex cost of setting the capital utilization rate to $z$.

Impatient households do not accumulate capital and do not own finished good firms or land. In addition, their maximum borrowing $b_{t}^{\prime}$ is given by the expected present value of their home times the loan-to-value (LTV) ratio $\mathrm{m}_{t}$ :

$$
\begin{gathered}
c_{t}^{\prime}+q_{t} h_{t}^{\prime}-b_{t}^{\prime}=w_{c, t}^{\prime} n_{c, t}^{\prime} / X_{w c, t}^{\prime}+w_{h, t}^{\prime} n_{h, t}^{\prime} / X_{w h, t}^{\prime}+q_{t}\left(1-\delta_{h}\right) h_{t-1}^{\prime}-R_{t-1} b_{t-1}^{\prime} / \pi_{t}+D i v_{t}^{\prime} \\
b_{t}^{\prime} \leq \mathrm{m}_{t} E_{t}\left(\frac{q_{t+1} h_{t}^{\prime} \pi_{t+1}}{R_{t}}\right)
\end{gathered}
$$

Shocks to the LTV ratio are governed by an autoregressive process of order 1 given by

$$
\log \mathrm{m}_{t}=\left(1-\rho_{m}\right) \log \overline{\mathrm{m}}+\rho_{m} \mathrm{~m}_{t-1}+u_{m, t}
$$

where $u_{m, t}$ is an i.i.d. process with variance $\sigma_{m}^{2}$.

\section{$3.2 \quad$ Firms}

To allow for nominal price rigidities, the model differentiates between competitive flexible price/wholesale firms that produce wholesale consumption goods and housing using two distinct technologies, and a final good firm that operates in the consumption sector under monopolistic competition. Wholesale firms hire labor and capital services and purchase intermediate goods to produce wholesale goods $Y_{t}$ and new houses $I H_{t}$. They solve:

$$
\max \frac{Y_{t}}{X_{t}}+q_{t} I H_{t}-\left(\sum_{i=c, h} w_{i, t} n_{i, t}+\sum_{i=c, h} w_{i, t}^{\prime} n_{i, t}^{\prime}+\sum_{i=c, h} R_{i, t} z_{i, t} k_{i, t-1}+R_{l, t} l_{t-1}+p_{b, t} k_{b, t}\right)
$$

Above, $X_{t}$ is the markup of final over wholesale goods. The production technologies are:

$$
\begin{gathered}
Y_{t}=\left(\mathrm{A}_{c, t}\left(n_{c, t}^{\alpha} n_{c, t}^{1-\alpha}\right)\right)^{1-\mu_{c}}\left(z_{c, t} k_{c, t-1}\right)^{\mu_{c}} \\
I H_{t}=\left(\mathrm{A}_{h, t}\left(n_{h, t}^{\alpha} n_{h, t}^{\prime 1-\alpha}\right)\right)^{1-\mu_{h}-\mu_{b}-\mu_{l}}\left(z_{h, t} k_{h, t-1}\right)^{\mu_{h}} k_{b, t}^{\mu_{b}} l_{t-1}^{\mu_{l}} .
\end{gathered}
$$

In (15), the non-housing sector produces output with labor and capital. In (16), new homes are produced with labor, capital, land and the intermediate input $k_{b}$. The terms $\mathrm{A}_{c, t}$ and $\mathrm{A}_{h, t}$ measure trend productivity in the non-housing and housing sector, respectively. 


\subsection{Nominal Rigidities and Monetary Policy}

There are Calvo-style price rigidities in the non-housing consumption sector and wage rigidities in both sectors. Final good firms buy wholesale goods $Y_{t}$ from wholesale firms in a competitive market, differentiate the goods at no cost, and sell them at a markup $X_{t}$ over the marginal cost. The CES aggregates of these goods are converted back into homogeneous consumption and investment goods by households. Each period, a fraction $1-\theta_{\pi}$ of retailers set prices optimally, while a fraction $\theta_{\pi}$ cannot do so, and index prices to the previous period inflation rate with an elasticity equal to $\iota_{\pi}$. The resulting consumption-sector Phillips curve is:

$$
\log \pi_{t}-\iota_{\pi} \log \pi_{t-1}=\beta G_{C}\left(E_{t} \log \pi_{t+1}-\iota_{\pi} \log \pi_{t}\right)-\varepsilon_{\pi} \log \left(X_{t} / \bar{X}\right)
$$

where $\varepsilon_{\pi}=\frac{\left(1-\theta_{\pi}\right)\left(1-\beta G_{C} \theta_{\pi}\right)}{\theta_{\pi}}$ measures the sensitivity of inflation to changes in the markup, $X_{t}$, relative to its steady-state value, $\bar{X}$.

Wage setting is modeled in an analogous way. Households supply homogeneous labor services to unions. The unions differentiate labor services as in Smets and Wouters (2007), set wages subject to a Calvo scheme and offer labor services to labor packers who reassemble these services into the homogeneous labor composites $n_{c}, n_{h}, n_{c}^{\prime}, n_{h}^{\prime}$. Wholesale firms hire labor from these packers. Under Calvo pricing with partial indexation to past inflation, the pricing rules set by the union imply four wage Phillips curves that are isomorphic to the price Phillips curve.

Monetary policy follows a modified Taylor rule that allows for interest rate smoothing and responds to inflation and GDP growth, subject to the zero lower bound (ZLB):

$$
R_{t}=\max \left[1, R_{t-1}^{r_{R}} \pi_{t}^{\left(1-r_{R}\right) r_{\pi}}\left(\frac{G D P_{t}}{G_{C} G D P_{t-1}}\right)^{\left(1-r_{R}\right) r_{Y}} \overline{r r}^{1-r_{R}}\right]
$$

GDP is the weighted average of output in the two sectors with nominal share weights fixed at their values in the non-stochastic steady state. The term $\overline{r r}$ is the steady-state real interest rate in gross terms. In the sensitivity analysis section we study the marginal contribution of the zero lower bound to the asymmetries.

\subsection{Market Clearing Conditions and Equilibrium}

The goods market produces consumption, business investment and intermediate inputs. The housing market produces new homes $I H_{t}$. The equilibrium conditions are:

$$
C_{t}+I K_{c, t} / \mathrm{A}_{k, t}+I K_{h, t}+k_{b, t}=Y_{t}-\phi_{t}
$$




$$
H_{t}-\left(1-\delta_{h}\right) H_{t-1}=I H_{t}
$$

together with the loan market equilibrium condition. Above, $C_{t}=c_{t}+c_{t}^{\prime}$ is aggregate consumption, $H_{t}=h_{t}+h_{t}^{\prime}$ is the aggregate stock of housing, and $I K_{c, t}=k_{c, t}-\left(1-\delta_{k c}\right) k_{c, t-1}$ and $I K_{h, t}=k_{h, t}-\left(1-\delta_{k h}\right) k_{h, t-1}$ are the two components of business investment. Total land is fixed and normalized to one.

A competitive equilibrium consists of sequence of prices and allocations such that, taking prices as given, the allocations solve the optimization problems for households and firms, the markets clear, and the monetary policy rule and borrowing constraints are satisfied at all times, given initial conditions and sequences of shocks.

\subsection{Calibration and Solution}

Iacoviello and Neri estimated the model with full information Bayesian methods on U.S. data running from 1965:Q1 to 2006:Q4. ${ }^{9}$ We set the model's parameters at the mean of the posterior distributions estimated in their paper. For completeness, their estimated parameter values are reported in the left column of Table 1.

Some parameter choices are based on information complementary to the estimation sample. These parameters are: the discount factors $\beta$ of the patient agents, the weight on housing in the utility function $j$, the technology parameters $\mu_{c}, \mu_{h}, \mu_{l}, \mu_{b}, \delta_{h}, \delta_{k c}, \delta_{k h}$, the steady-state gross price and wage markups $\bar{X}, \bar{X}_{w c}, \bar{X}_{w h}$. The persistence of the housing preference shock is set at $\rho_{j}=0.96$, following Iacoviello and Neri (2010). The persistence of the LTV shock is set at $\rho_{m}=0.975$, a rather high value that captures the idea that changes in credit conditions are persistent over time. Values for all the calibrated parameters are summarized in the right column of Table 1.

In a few cases, we depart from the full-information estimates as described below. We set $\overline{\mathrm{m}}$, the steady-state value of the LTV ratio, equal to 0.925 , a parameter that better captures the financial innovation of the period from the 1980s onwards. The wage share of credit constrained households, $1-\alpha$, is estimated by Iacoviello and Neri (2010) to be around 20 percent. Here, we set this share at 40 percent in the non-stochastic steady state. When the model is solved with first-order perturbation methods, the fraction of constrained agents and the severity of the borrowing constraint remain constant over the cycle. When the collateral constraint binds only

\footnotetext{
${ }^{9}$ Iacoviello and Neri (2010) include in the estimation 10 observed series and 10 exogenous shocks, and discuss estimation method and results, including the relative importance of different sources of fluctuations. Given our different focus on highlighting asymmetries implied by collateral constraints, we do not report here their estimation results concerning the parameters of the model governing the exogenous shocks.
} 
occasionally, shocks that increase the value of the housing collateral can make the borrowing constraint slack. Hence, the fraction of credit constrained agents is time-varying and our calibration only provides an upper bound on the fraction of credit-constrained agents.

A key parameter in determining the extent of the asymmetries is the discount factor of the impatient agents, $\beta^{\prime}$. Values of this parameter that fall below a certain threshold imply that impatient agents never escape the borrowing constraint. Then, the model has no asymmetries, regardless of the size of the shocks, and produces a large correlation between housing price growth and consumption growth, since the borrowing constraint holds all the time with equality. Conversely, when $\beta^{\prime}$ takes on higher values, closer to discount factor of patient agents, smaller increases in house prices suffice to make the borrowing constraint slack (even though the constraint is expected to bind in the long run). The slack borrowing constraint, in turn, reduces the comovement between house prices and consumption as well as the volatility of aggregate consumption. We set $\beta^{\prime}$ equal to 0.988 , based on the moment matching exercise described below.

The proliferation of state variables renders standard global solution algorithms inoperable. Moreover, the occasionally binding constraint on borrowing and the non-negativity constraint on the policy interest rate make first-order perturbation methods inapplicable. We solve the model using the piecewise linear method described in Appendix B. This approach is common in the literature on the zero lower bound on nominal interest rates. For instance, see Eggertsson and Woodford (2003), Christiano, Eichenbaum, and Rebelo (2011) and Bodenstein, Guerrieri, and Gust (2013). To assess the performance of the piecewise algorithm, we compare the piecewise linear solution of the basic model of Section 2 against the virtually exact solution of the same model obtained with global methods. Details of this comparison are in Appendix C.

\section{Results of the Full Model}

First, we complete the calibration of the model through a moment matching exercise. Second, we use a simple non-linear VAR to investigate the asymmetric relationship between house prices and consumption. The VAR implied by population moments from our model captures asymmetric responses of consumption to house price increases and declines. The VAR estimated on the observed data sample is consistent with its model counterpart. 


\subsection{A Moment Matching Exercise}

We use the model to generate data conditional on the two sources of stochastic variation, the LTV ratio shock, $\mathrm{m}_{t}$, and housing preference shock, $\mathrm{j}_{t}$. We choose the standard deviations of the two shocks and the discount factor of the impatient agents $\beta^{\prime}$ in order to optimize the model's ability to account for the volatility of consumption and house prices and their correlation. As mentioned above, higher values of the discount factor work to reduce both the volatility of consumption and the correlation between consumption and house prices. Importantly, we do not impose any requirements on the model's ability to fit higher moments in the data, such as asymmetries in the responses to shocks.

The metric used in our optimization procedure is $\mathcal{L}(s s)$, where $s s$ is the vector including estimates of $\sigma_{j}, \sigma_{m}, \beta^{\prime}$ and $\mathcal{L}(s s)$ is given by

$$
\mathcal{L}(s s)=(\widehat{m m}-\mathbf{f}(s s)) \widehat{I}^{-1}(\widehat{m m}-\mathbf{f}(s s))^{\prime}
$$

Here, $\widehat{m m}$ is a $3 \times 1$ vector that includes the empirical standard deviations of quarterly consumption growth and quarterly real house price growth, as well as their correlation. ${ }^{10}$ The $3 \times 3$ matrix $\widehat{I}$ is the identity matrix. Finally, $\mathbf{f}(s s)$ is a $3 \times 1$ vector with moments analogous to the ones in $\widehat{\mathrm{mm}}$ but implied by the model in population (with all other parameters set as described in the calibration section above).

The parameter values that minimize $\mathcal{L}(s s)$ are $\sigma_{j}=0.086, \sigma_{m}=0.022$, and $\beta^{\prime}=0.988$. At the estimated values, the standard deviations of quarterly consumption growth and house price growth implied by the model in population are 0.63 and 1.77 percent, equal to their observed sample counterparts. Moreover, the correlation of consumption growth and house price growth implied by the model is 0.39 , as in the data. Finally, the magnitudes of the standard deviation of the shocks imply that housing preference shocks explain virtually all of the volatility in house prices, while credit shocks account for most - two thirds - of the variance of consumption.

\subsection{A Nonlinear VAR}

Using the model estimates, we generate artificial time-series on consumption and house prices that we fit to a two-variable, nonlinear VAR. We then compare the VAR estimates with their data counterparts. Each equation in the VAR regresses linearly detrended consumption and house prices on: a constant, the linearly detrended consumption, and distinct terms for positive

\footnotetext{
10 The data sample and variable definitions are described in the note to Figure 1.
} 
and negative lagged deviations of house prices from a linear trend. ${ }^{11}$ Innovations to each equation are orthogonalized using a Cholesky scheme: we treat model and data symmetrically, by imposing an ordering scheme such that a "house price shock" affects contemporaneously both house prices and consumption. None of the qualitative results is sensitive to the particular orthogonalization scheme adopted.

Figure 3 shows population estimates from the model against estimates for U.S. data running from 1976 to 2011 and $95 \%$ bootstrap confidence bands. The beginning of the sample is motivated by the earliest availability of the CoreLogic House Price Index. The top panels focus on innovations to house prices that yield a 2 standard deviation increase in house prices. The bottom panels show responses to an innovation that yields a 2 standard deviation decline in house prices. Strikingly, model and data appear in substantial agreement: the response of consumption to a large house price decline is about twice as large as that to a large house price increase of equal magnitude, in the model as in the data, despite the fact that the asymmetry was not a requirement of the estimation exercise. Furthermore, for the estimates based on observed data, we compute confidence intervals for the difference between the peak response of the absolute value of consumption to the positive and negative innovations. We confirm that this difference is statistically different from zero at standard significance levels. Accordingly, the null hypothesis of asymmetric responses is not rejected.

\subsection{Responses to Positive and Negative Shocks}

To illustrate the fundamental source of the asymmetry in the model, Figure 4 considers the effects of a shock to housing preferences, the process $\mathbf{j}_{t}$ in (9), which we interpret as a shock to housing demand. Between periods 1 and 8 , a series of innovations to $\mathrm{j}_{t}$ are set to bring about a decline in house prices of 10 percent. ${ }^{12}$ Thereafter, the shock follows its autoregressive process. In this case, the decrease in house prices reduces the collateral capacity of constrained households. Accordingly those households can borrow less and are forced to curtail their non-housing consumption even further in order to comply with the borrowing constraint. On balance, the decline in aggregate consumption is close to 2.5 percent. The model's short-run nominal and

\footnotetext{
${ }^{11}$ In other words, the right-hand side variables in the VAR are (aside from the constant term) the lag of $c_{t}$, $\max \left(q_{t}, 0\right)$, and $\min \left(q_{t}, 0\right)$, where $c_{t}$ and $q_{t}$ denote the $\log$ deviations of consumption and house prices from their respective linear trends.

12 According to the estimated value of $\sigma_{j}$, a positive one-standard deviation innovation to housing preferences leads to an immediate increase in house prices of about 4 percent, before house prices revert to their initial value. We choose the sequence in figure 4, with i.i.d. shocks phased in over several quarters - and with a cumulative effect of roughly two standard deviations -, to better mimic a persistent episode of house price appreciation as in the 2002-2006 housing price boom. We use the same procedure for the credit shock described later.
} 
real rigidities imply that the decline in aggregate consumption translates into a decline in the firms' demand for labor. In equilibrium, the drop in hours worked comes close to reaching 2.5 percent below the balanced growth path. In reaction to a shock of this magnitude, the zero lower bound on interest rates is not attained, therefore the asymmetric responses are only driven by the collateral constraint.

Unforeseen to the agents in the model, in period 51 a series of innovations for the shock to housing preferences brings about a 10 percent increase in house prices over the next 8 quarters. Recalling the partial equilibrium model described in Section 2, an increase in house prices can relax borrowing constraints. Accordingly, the borrowing constraint for the impatient household becomes slack, and the Lagrange multiplier in the households' utility maximization problem bottoms out at zero, before taking on positive values again as house prices return to the baseline. When the constraint is slack, the borrowing constraint channel remains operative only in expectation. Thus, impatient households discount that channel more heavily the longer the constraint is expected to remain slack. As a consequence, the response of consumption to the large house price increases considered in the figure is not as dramatic as the reaction to house price declines of an equal magnitude. At peak, the increase both in consumption and hours worked is about 0.5 percent, much smaller than the response to the house price decline.

In Appendix D we show the impulse responses to negative and positive credit shocks. Credit shocks explain a negligible fraction (about 1 percent) of the volatility in house prices, and, in line with our moment matching exercise, mostly account for the residual volatility in consumption not captured by housing preference shocks. A reduction in the maximum LTV ratio leads to a decrease in borrowing, consumption and house prices. Positive shocks to credit supply make the borrowing constraint temporarily slack and produce smaller effects on consumption than negative shocks, while they cause house prices to initially fall before they rise. According to the estimated model, credit shocks directly affect the maximum resources that borrowers can use to finance expenditure, and shift demand away from housing towards consumption. Their overall effect on house prices is small, and can be even negative if the collateral constraint becomes slack for a sufficiently long period of time. ${ }^{13}$.

In experiments not reported here, we have found modest asymmetries for other shocks that affect house prices and consumption in our general equilibrium model. These shocks are likely to generate significant asymmetries only insofar as they affect house prices or collateral capacity. However, the asymmetry that we uncover is independent of the particular stochastic structure for the model, and needs not rely on housing demand shocks only. Potentially, in any

\footnotetext{
13 The finding that in DSGE models of this kind, changes in credit conditions seem to have modest effects on housing prices mirrors analogous conclusions by Justiniano, Primiceri, and Tambalotti (2013).
} 
housing model with occasionally binding constraints, one can find important macroeconomic asymmetries as long as the model can match the observed swings in house prices.

\subsection{Sensitivity Analysis}

Figures 5 and 6 study the sensitivity of consumption to different shock sizes and parameter values. To isolate the contribution of borrowing constraints to asymmetries from that of the zero lower bound, the figures abstract from the ZLB. Given the estimates, the borrowing constraint is slack, on average, 68 out of every 100 periods and the nominal interest rate hits the zero lower bound about 1 period out of every 100. Accordingly, the collateral constraint is the main driver of macroeconomic asymmetries in the model.

Figure 5 plots the peak response of consumption to a housing demand shock as a function of the change in house prices induced by the same shock. The figure also shows the relationship between the peak elasticity of consumption to housing wealth as a function of the peak impact to housing wealth. The former is defined as the ratio of the peak response of aggregate consumption to the peak response of house wealth, the latter as the peak response of the value of the housing stock. In our model, if borrowing constraints were always binding, this elasticity would be constant, regardless of the change in house prices. However, because large increases in house prices can make the borrowing constraint slack, they affect consumption less and less in proportion. Mechanically, the peak impact on consumption elasticity of a housing demand shock continues to decline because our solution algorithm attributes a longer duration to the regime with slack borrowing constraints when the house price increases become larger.

Figure 6 considers again the peak impact of consumption relative to the peak impact on house prices of a housing demand shock. For ease of comparison, the blue solid line reproduces the benchmark results shown in Figure 5. In addition, Figure 6 considers two alternative calibrations. The line labeled "High Impatience" focuses on a lower discount factor for impatient agents, setting $\beta^{\prime}$ equal to 0.98. Focusing on the bottom panel of the figure, with greater impatience, larger increases in house prices are required to relax the borrowing constraint. Accordingly, the peak elasticity of consumption to housing wealth remains constant for larger increases in housing wealth than under the benchmark calibration. Moreover, even when the borrowing constraint is eventually relaxed by larger housing demand shocks, the constraint is expected to stay slack for a shorter period than under the benchmark. These differences are reflected in the top panel. The flattening out of the response of consumption to increases in housing wealth becomes less pronounced.

Figure 6 also shows the results for a lower value of the LTV ratio, with $\overline{\mathrm{m}}$ equal to 0.75 . When 
increases in housing wealth make the borrowing constraint slack, there are little differences between the benchmark and the results under this alternative calibration. If anything, for large increases in house prices, the response of consumption is stronger, since the borrowing constraint is likely to be less slack, and the collateral effect stronger, for low values of the LTV ratio. However, when housing wealth declines, the collateral effect is smaller, and the decrease in borrowing is less pronounced. Accordingly, lower values for $\overline{\mathrm{m}}$ also imply a flattening of the response of consumption to increases in housing wealth and a compression of the asymmetry that we have highlighted so far.

Figure 7 isolates the contribution of the zero lower bound on interest rates in generating the asymmetric response of macroeconomic variables to changes in housing wealth. In the ZLB case, declines in house prices exceeding 10 percent in magnitude bring the gross policy rate $R_{t}$ to 1 (equivalently, the net policy rate hits zero). With mechanisms familiar from the literature on the effects of aggregate demand shocks in a liquidity trap, ${ }^{14}$ the spillover effects of contractionary housing demand shocks onto aggregate consumption become amplified. At the zero lower bound with constant nominal rates, declines in inflation can bring up real interest rates and deepen the contractionary effects of the shock. We pick up this theme again below when we discuss our estimates from panel regressions on regional data.

\section{$5 \quad$ Regional Evidence on Asymmetries}

Our model and the evidence from the vector autoregressions at the national level motivate additional empirical analysis that we conduct using a panel of data from U.S. states and Metropolitan Statistical Areas (MSA). The advantage of these data is that variation in house prices and economic activity is greater at the regional than at the aggregate level, as documented for instance by Del Negro and Otrok (2007), who find a large degree of heterogeneity across states in regard to the relative importance of the national factors. ${ }^{15}$ The use of regional data also allays the concern that little can be learned from national data, given the rarity of declines in house prices at the national level. Note that, in any event, the state-level series aggregated back to the national level track their National Income and Product Accounts (NIPA) counterparts rather well. ${ }^{16}$

\footnotetext{
${ }^{14}$ For instance, see Christiano, Eichenbaum, and Rebelo (2011).

${ }^{15}$ In the sample period we analyze, the first principal component for annual house price growth accounts for 64 percent of the variance of house prices across the 50 U.S. states and the District of Columbia. The corresponding numbers for employment in the service sector, auto sales, electricity consumption, and mortgage originations are respectively $73,90,44$, and 89 percent.

${ }^{16}$ For instance, over the sample period, the correlation between NIPA motor vehicle consumption growth (about $1 / 3$ of total durable expenditure) and retail auto sales growth is 0.89 ; and the correlation between
} 
To set the stage, Figure 8 shows changes in house prices and several measures of activity, namely changes in employment in the service sector, auto sales, electricity consumption, and mortgage originations. The figure focuses on two points in time, 2005 and 2008 for all the 50 U.S. states and the District of Columbia. For each state there are two dots in each panel: the green dot (concentrated in the north-east region of the graph) shows the lagged percent change in house prices and the percent change in the indicator of economic activity in 2005, at the height of the housing boom. ${ }^{17}$ The red dot represents analogous observations for the 2008 period, in the midst of the housing crash. Fitting a piecewise linear regression to these data yields a correlation between house prices and activity that is smaller when house prices are high. This evidence on asymmetry is bolstered by the large cross-sectional variation in house prices across states over the period in question.

\subsection{State-Level Evidence}

We use annual data from the early 1990s to 2011 from the 50 U.S. states and the District of Columbia on house prices and measures of economic activity. We choose measures of economic activity to match our model counterparts for consumption, employment and credit.

Our main specification takes the following form:

$$
\Delta \log y_{i, t}=\alpha_{i}+\gamma_{t}+\beta_{P O S} \mathcal{I}_{i, t} \Delta \log h p_{i, t-1}+\beta_{N E G}\left(1-\mathcal{I}_{i, t}\right) \Delta \log h p_{i, t-1}+\delta X_{i, t-1}+\varepsilon_{i, t}
$$

where $y_{i, t}$ is an index of economic activity and $h p_{i, t}$ is the inflation-adjusted house price index in state $i$ in period $t ; \alpha_{i}$ and $\gamma_{t}$ represent state and year fixed effects; and $X_{i, t}$ is a vector of additional controls. We interact changes in house prices with a state-specific indicator variable $\mathcal{I}_{i, t}$ that, in line with the model predictions, takes value 1 when house prices are high, and value 0 when house prices are low. We classify house prices as high in a particular state when house prices are above a state-specific linear trend separately estimated for the 1976-2011 period. Using this approach, the fraction of states with high house prices is about 20 percent in the 1990s, rising gradually to peak at 100 percent in 2005 and 2006, and dropping to 27 percent at the end of the sample. Our results were similar using two alternative definitions of $\mathcal{I}_{i, t}$. Under the first alternative definition, $\mathcal{I}_{i, t}$ equals 1 when real house price inflation is positive. Under the second definition, $\mathcal{I}_{i, t}$ equals 1 when the ratio of house prices to income is high relative to its trend (in $\log$ ). In our baseline specification, we use one-year lags of house prices and other

services consumption growth and electricity usage growth is 0.54 .

${ }^{17}$ An analogous relationship is more tenuous for house prices and employment in the manufacturing goods sector. Most goods are traded and are less sensitive to local house prices than services. 
controls to control for obvious endogeneity concerns. Our results were also little changed when instrumenting current or lagged house prices with one or more lags.

Tables 2 to 4 present our estimates when the indicators of economic activity $y_{i, t}$ are employment in the service sector, auto sales, and electricity usage respectively.

Table 2 presents the results when the measure of regional economic activity is employment in the non-tradeable service sector. We choose this measure (rather than total employment) since U.S. states (and MSAs) trade heavily with each other, so that employment in sectors that mainly cater to the local economy better isolates the local effects of movements in local house prices. ${ }^{18}$ The first two columns do not control for time effects. They show that the asymmetry is strong and economically important, and that house prices matter, at statistically conventional levels, both when high and when low. After controlling for time effects in the third column, the coefficient on high house prices is little changed, but the coefficient on low house prices is lower. A large portion of the declines in house prices in our sample took place against the background of the zero lower bound on policy interest rates. As discussed in the model results, the zero lower bound is a distinct source of asymmetry for the effect of change in house prices. Time fixed effects allow us to parse out the effects of the national monetary policy reaching the zero lower bound and, in line with our theory, compress the elasticity of employment to low house prices. In the last two columns, after adding additional variables, the only significant coefficient is the one on low house prices. In column five, the coefficient on high house prices is positive, although it is low and not significantly different from zero. The coefficient on low house prices, instead, is positive and significantly different from zero. These results imply that house prices only matter for economic activity when they are low. The difference in the coefficient on low and high house prices is significantly different from zero.

Table 3 reports our results when the measure of activity is retail automobile sales. Auto sales are an excellent indicator of local demand, since autos are almost always sold to state residents, and since durable goods are notoriously sensitive to changes in economic conditions. After adding lagged car sales and personal income as controls, the coefficients on low and high house prices are both positive, but the coefficient on low house prices (estimated at 0.2 ) is nearly three times as large.

18 The BLS collects state-level employment data by sectors broken down according to NAICS (National Industry Classification System) starting from 1990. According to this classification (available at http://www.bls.gov/ces/cessuper.htm), the goods-producing sector includes Natural Resources and mining, construction and manufacturing. The service-producing sector includes wholesale trade, retail trade, transportation, information, finance and insurance, professional and business services, education and health services, leisure and hospitality and other services. A residual category includes unclassified sectors and public administration. We exclude from the service sector wholesale trade (which on average accounts for about 6 percent of total service sector employment) since wholesale trade does not necessarily cater to the local economy. 
Table 4 reports our results using residential electricity usage as a proxy for consumption. Even though electricity usage only accounts for 3 percent of total consumption, we take electricity usage to be a useful proxy for nondurable consumption. ${ }^{19}$ Most economic activities involve the use of electricity, and electricity cannot be easily stored. Accordingly, the flow usage of electricity may even provide a better measures of the utility flow derived from a good than the actual purchase of the good. Even in cases when annual changes in weather conditions may affect year-on-year consumption growth, their effect can be easily filtered out using state-level observations on heating and cooling degree days, which are conventional measures of weatherdriven electricity demand. We use these weather measures as controls in all specifications reported. As the table shows, in all regressions low house prices affect consumption growth more than high house prices. After time effects, lagged income growth and lagged consumption growth are controlled for (last column), the coefficient on high house prices is 0.11 , the coefficient on low house prices is nearly twice as large at 0.18 , and their difference is statistically larger than 0 at the 10 percent significance level.

Because the effects of low and high house prices on consumption work in our model through tightening or relaxing borrowing constraints, it is important to check whether measures of leverage also depend asymmetrically on house prices. We perform these checks and report the results in Appendix E, which confirms that mortgage originations depend asymmetrically on house prices too.

\subsection{MSA-Level Evidence}

Tables 5 and 6 present the results of evidence across MSAs. MSAs account for about 80 percent of the population and of employment in the entire United States. In Table 5, the results from the MSA-level regressions reinforce those obtained at the state level. After controlling for income, lagged employment and time effects, the elasticities of employment to house prices are 0.05 and 0.09 when house prices are high and low, respectively. These elasticities are larger than those found at the state level.

A legitimate concern with the panel and time-series regressions discussed so far is that the correlation between house prices and economic activity could be due to some omitted factor that simultaneously drives both house prices and economic activity. Even if this were the case, our regressions would still be of independent interest, since - even in absence of a causal relationship - they would indicate that comovement between house prices and economic activity is larger

\footnotetext{
${ }^{19}$ Da and Yun (2010) show that using electricity to proxy for consumption produces asset pricing implications that are consistent with consumption-based capital asset pricing models.
} 
when house prices are low, as predicted by the model.

To support claims of causality, one needs to isolate exogenous from endogenous movements in house prices. In Table 6, we follow the methodology and insight of Mian and Sufi (2011) and use data from Saiz (2010) in an attempt to distinguish an independent driver of housing demand that better aligns with its model counterpart. The insight is to use the differential elasticity of housing supply at the MSA level as an instrument for house prices, so as to disentangle movements in housing prices due to general changes in economic conditions from movements in the housing market that are directly driven by shifts in housing demand in a particular area. Because such elasticity is constant over time, we cannot exploit the panel dimension of our dataset, and instead use the elasticity in two separate periods by running two distinct regressions of car sales on house prices. The first regression is for the 2002-2006 housing boom period, the second for the 2006-2010 housing bust period. In practice, we rely on the following differenced instrumental variable specifications:

$$
\begin{aligned}
\log h p_{t}-\log h p_{s} & =b_{0}+b_{1} \text { Elasticity }+\varepsilon_{b} \\
\log c a r_{t}-\log c a r_{s} & =c_{0}+c_{1}\left(\log h p_{t}-\log h p_{s}\right)+\varepsilon_{c}
\end{aligned}
$$

where $s=2002$ and $t=2006$ in the first set of regressions, and $s=2006$ and $t=2010$ in the second set.

The first stage, OLS regressions show that elasticity is a powerful instrument in driving house prices, with an $R^{2}$ from the first stage regression around 0.20 in both subperiods. ${ }^{20}$ The second stage regressions show how car sales respond to house prices dramatically more in the second period, in line with the predictions of the model and with the results of the panel regressions. In the $2002-2006$ period, the elasticity of car sales to house prices is 0.24 . In the 2006 - 2010 period, in contrast, this elasticity doubles to 0.46 .

Using a higher level of data disaggregation (ZIP-code level data instead of MSAs) and a sample that runs from 2007 to 2009, Mian, Rao, and Sufi (2012) find a large elasticity (equal to 0.74 ) of auto sales to housing wealth during the housing bust, in line with our findings. Importantly, they also find that this elasticity is smaller in zip codes with a high fraction of non-housing wealth to total wealth. One interpretation of their result - in line with our model - is that households in zip codes with high non-housing wealth might be, all else equal, less likely to face binding borrowing constraints during periods of housing price declines, because they can use other forms of wealth to support their consumption plans.

\footnotetext{
20 The $\mathrm{F}$ statistics on the first stage regressions are 69.1 and 67.2 for the first and the second period respectively, well above the conventional threshold of 10 for evaluating weak instruments.
} 


\section{Debt Relief and Borrowing Constraints}

So far, our theoretical and empirical results show that movements in house prices can produce asymmetries that are economically and statistically important. We now consider whether these asymmetries are also important for gauging the effects of policies aimed at the housing market in the context of a deep recession. To illustrate our ideas, we choose a simple example of one such policy, a lump-sum transfer from patient (saver) households to impatient (borrower) households. This policy could mimic voluntary debt relief from the creditors, or a scheme where interest income is taxed and interest payments are subsidized in lump-sum fashion, so that the end result is a transfer of resources from the savers to the borrowers.

We consider this experiment against two different baselines. In one case, house prices are assumed to be declining; in the other case, housing prices are assumed to be increasing. The baseline housing price changes are brought about by the same preference shocks considered in Figure 4 and discussed at length above.

Figure 9 shows the cumulative response of house prices to the baseline housing preference shocks and to two transfer shocks from saver households to borrower households. Both transfer shocks are unforeseen. They are sized at the same 1 percent of steady-state total consumption in both cases. Each transfer is governed by an auto-regressive process of order 1, with coefficient equal to 0.5. The first transfer starts in period 10. A series of unforeseen innovations to the shock process phases in the transfer, until it reaches a peak of 1 percent of steady-state consumption. Then, the auto-regressive component of the shock reduces the level of the transfer back to 0 . The first transfer happens against a background of housing price declines and tight borrowing constraints. The second transfer, starting in period 50, mimics the first but happens against a baseline with housing price increases and slack borrowing constraints.

The top left panel of Figure 9 shows house prices in deviation from their steady-state level. The path shown is almost identical to the one in Figure 4 because the transfer shocks only have a negligible effect on house prices. The transfer payments are timed to coincide with the series of housing preference shocks that reduce house prices.

The remaining panels in Figure 9 show responses of key variables to the transfer shock in deviation from the baseline path that occurs with the housing preference shock only. Thus, those panels isolate the partial effects of the transfer shocks. The consumption response of borrower households is dramatically different depending on the baseline variation in house prices. When house prices decline, the borrowing constraint is tight and the marginal propensity to consume of borrower households is elevated. When house prices increase, the borrowing constraint becomes slack and the marginal propensity to consume of borrower households drops down closer to that 
for saver households. In reaction to the transfer, consumption of the savers declines less, and less persistently, against a baseline of housing price declines. In that case, there are expansionary spillover effects from the increased consumption of borrowers to aggregate hours worked and output. Taking together the responses of savers and borrowers, the partial effects of the transfer on aggregate consumption are sizable when house prices are low, and negligible when house prices are elevated. As a consequence, actions such as mortgage relief can almost pay for themselves through their expansionary effects on aggregate economic activity in a scenario of severely binding borrowing constraints.

\section{Conclusions}

Numerous recent papers with an empirical focus have emphasized the importance of household debt and the housing market in understanding the Great Recession. Our model provides a framework to analyze these results. The model explains why household debt seems to matter more during severe recessions and it allows the assessment of costs and benefits of alternative policies aimed at restoring the efficient functioning of the housing market.

Our empirical and theoretical results indicate that policy measures aimed at the housing market can produce outsize spillovers to aggregate consumption in periods when collateral constraints are tight, either because of large declines in house prices or because credit supply standards have been made more stringent. These spillovers are likely to be larger than those that can be found in samples dominated by house price increases, because these periods can severely underpredict the sensitivity of consumption to movements in housing wealth.

Throughout the paper, we have emphasized the role of housing as collateral for households, and on the effects of changes in housing wealth on consumption. However, the mechanism at the heart of our argument has even broader applicability. For instance, to the extent that fixed assets are used for collateral by entrepreneurs, local governments, or exporters, the asymmetries highlighted here for consumption could also be relevant for fixed investment, government spending, or the trade balance. ${ }^{21}$

\footnotetext{
${ }^{21}$ See for instance Adelino, Schoar, and Severino (2013), Chaney, Sraer, and Thesmar (2012) for investment; Barboza (2011) for government spending; Klapper, Laeven, and Rajan (2012) for trade credit.
} 
Figure 1: House Prices and Consumption in U.S. National Data
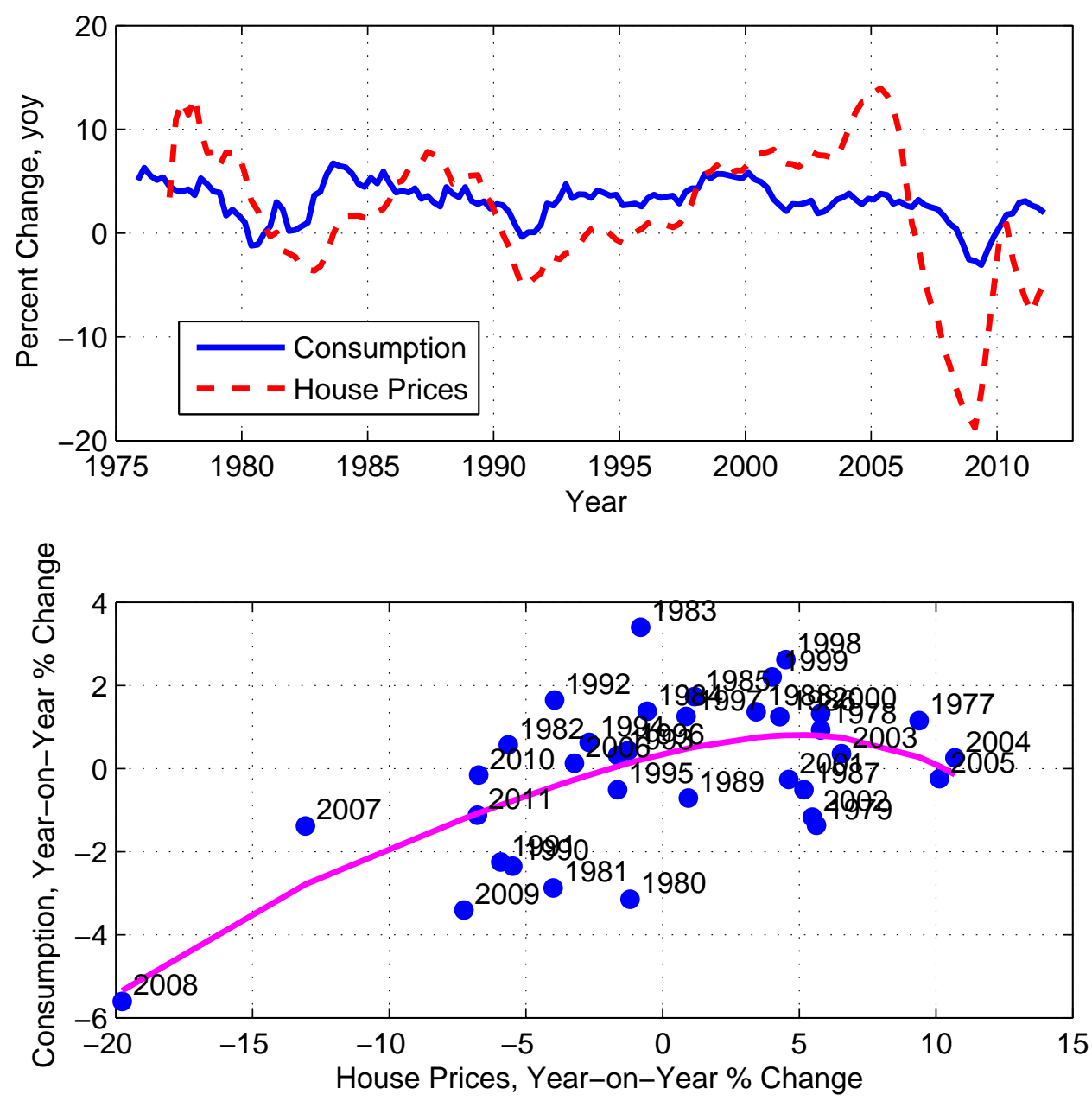

Note: Data sources are as follows. House Prices: Loan Performance National House Price Index (SA), Haver Analytics, USLPHPIS@USECON, divided by the GDP deflator (DGDP@USECON). Consumption: Real Personal Consumption Expenditures, from Department of Commerce, Bureau of Economic Analysis (CH@USECON). In the bottom panel, consumption growth and house price growth are expressed in deviation from their sample mean. The data sample is from 1976Q1 to 2011Q4. 
Figure 2: House Prices and Consumption in the Basic Model
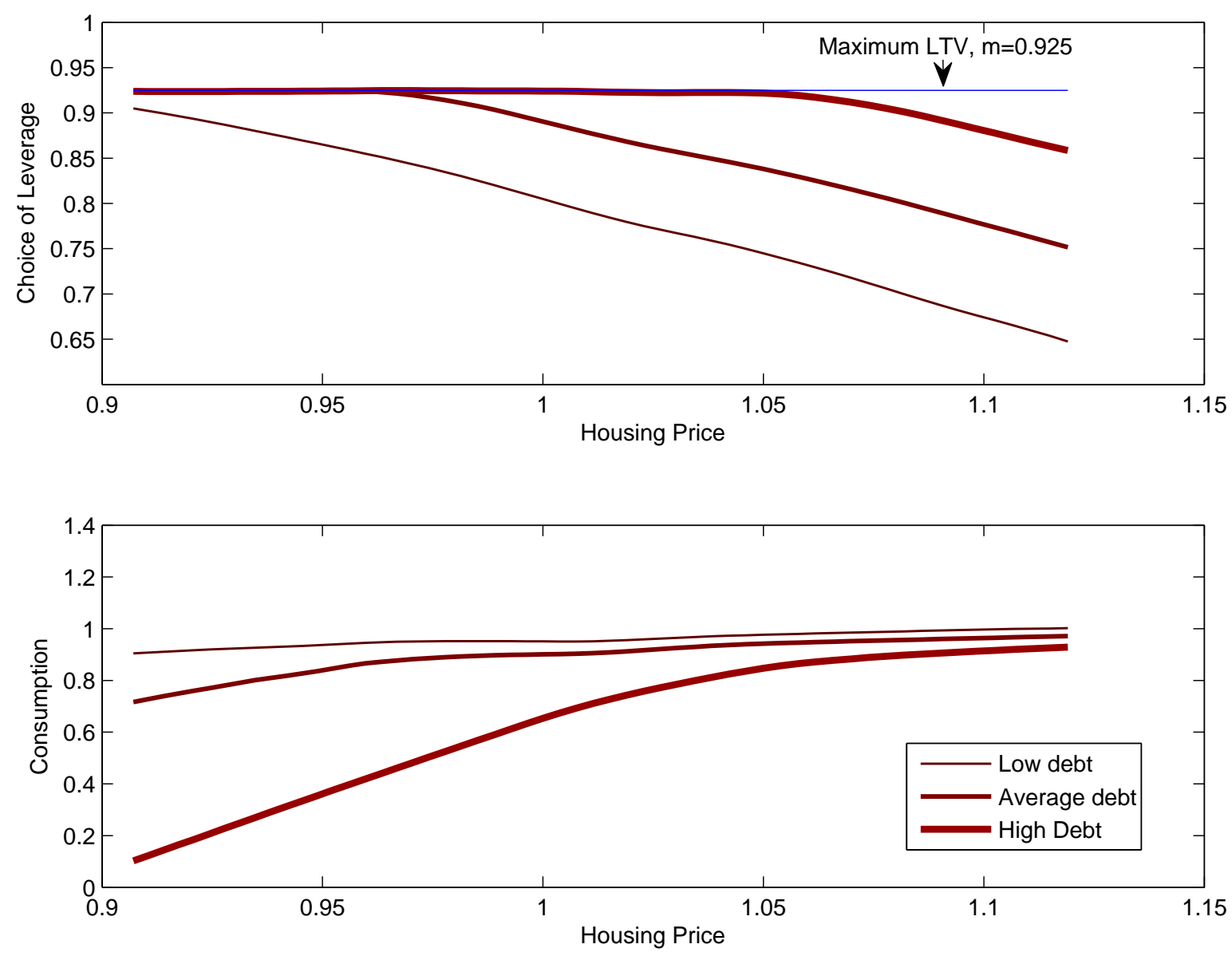

Note: Optimal leverage choice and optimal consumption as a function of the housing price for three different levels of debt, low, normal and high, when housing is at its nonstochastic steady-state value. In the top panel, low levels of house prices move the household closer to the maximum borrowing limit given by $m=0.925$. This is more likely to happen at high levels of debt (thick line). In the bottom panel, the higher house prices are, the more likely is the household not to be credit constrained, and the consumption function becomes flatter. At high levels of debt, the household is constrained for a larger range of realizations of house prices, and the consumption function is steeper when house prices are low. 
Figure 3: Estimates from Asymmetric VAR vs Model
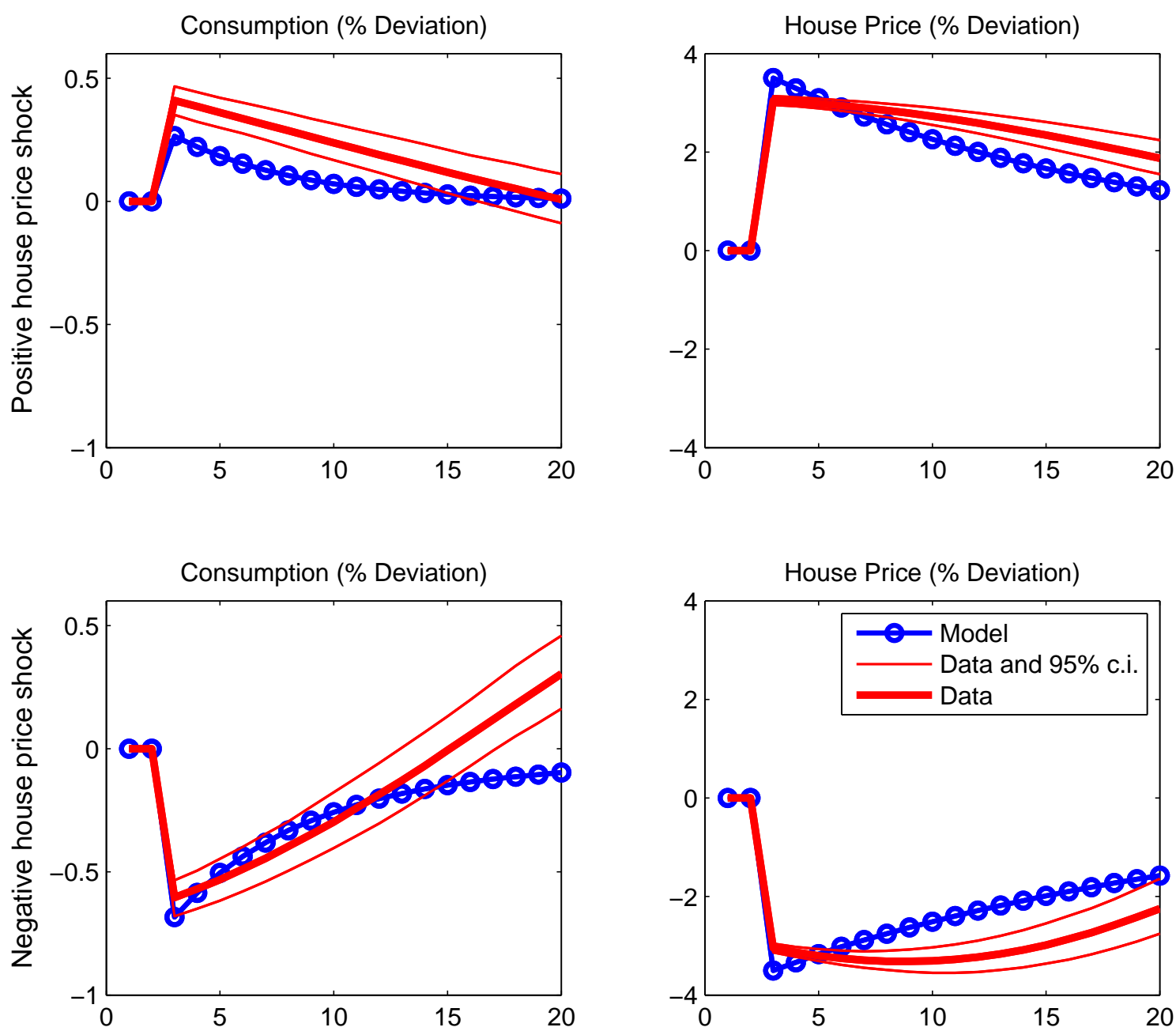

Note: Top row: Impulse Responses to a 2 standard error increase in house prices. Bottom row: Impulse Response to a 2 standard error decrease in house prices. Horizontal axis: quarters from the shock; vertical axis: percentage deviation from the unshocked path. Data VAR run using quarterly data for inflation-adjusted house prices and consumption (linearly detrended) from 1976Q1 to 2011Q4. Model VAR run using observations generated from a model simulation of 2,000 periods using the calibration in Table 1. 
Figure 4: Impulse Responses to Negative and Positive Housing Demand Shocks in the Full DSGE Model
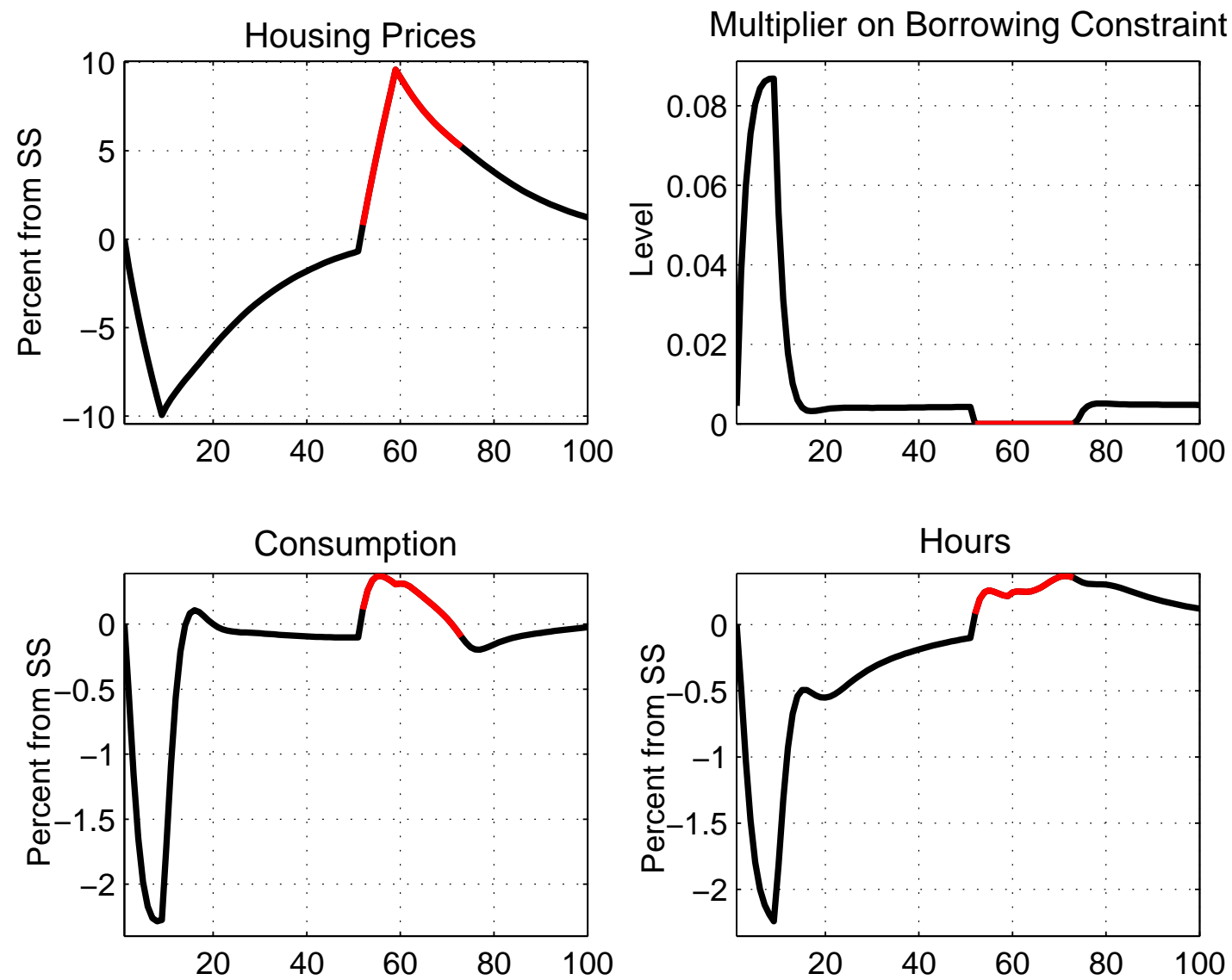

Note: Horizontal axis: horizon in quarters. The simulation shows the dynamic response of macroeconomic variables to two housing demand shocks that move the (log of the) housing preference parameter $j$ by about 2.5 standard deviations. In period 1 , a decline in housing demand causes house prices to drop by around 10 percent after 8 quarters. In period 50, an increase in housing demand causes house price to rise by around 10 percent. Variables are plotted in red when the collateral constraint is slack. 
Figure 5: Response of Consumption to Positive and Negative Changes in Housing Prices in the Full DSGE Model
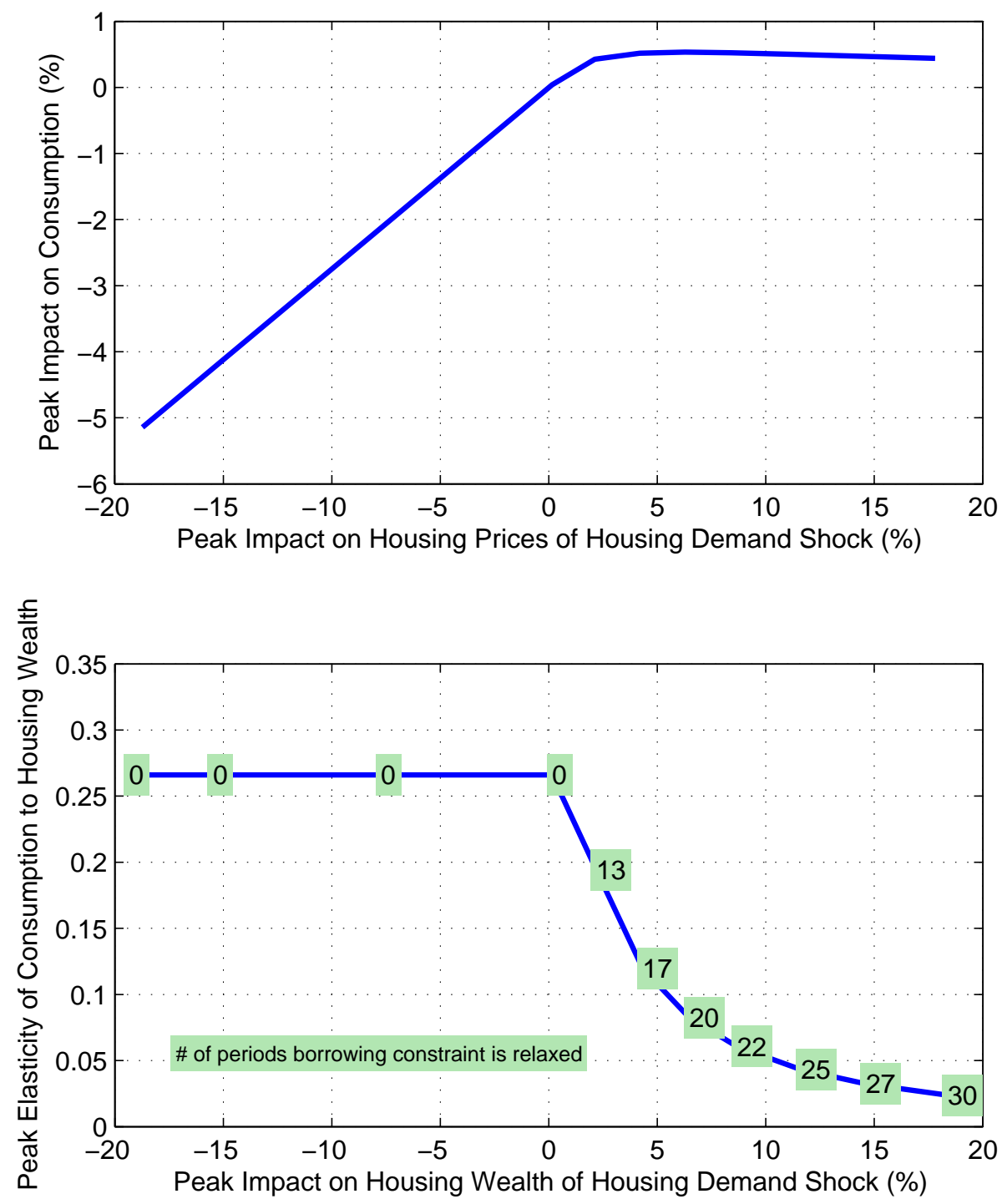

Note: The top panel plots the maximum response of consumption relative to the zero baseline following a housing price shock of size given by the x-axis. The bottom panel plots the maximum elasticity of consumption to housing wealth given a housing wealth shock of size given by the x-axis. The housing price and wealth shocks are caused by a housing preference shock. 
Figure 6: Response of Consumption to Positive and Negative Changes in Housing Prices in the Full DSGE Model. Sensitivity Analysis.
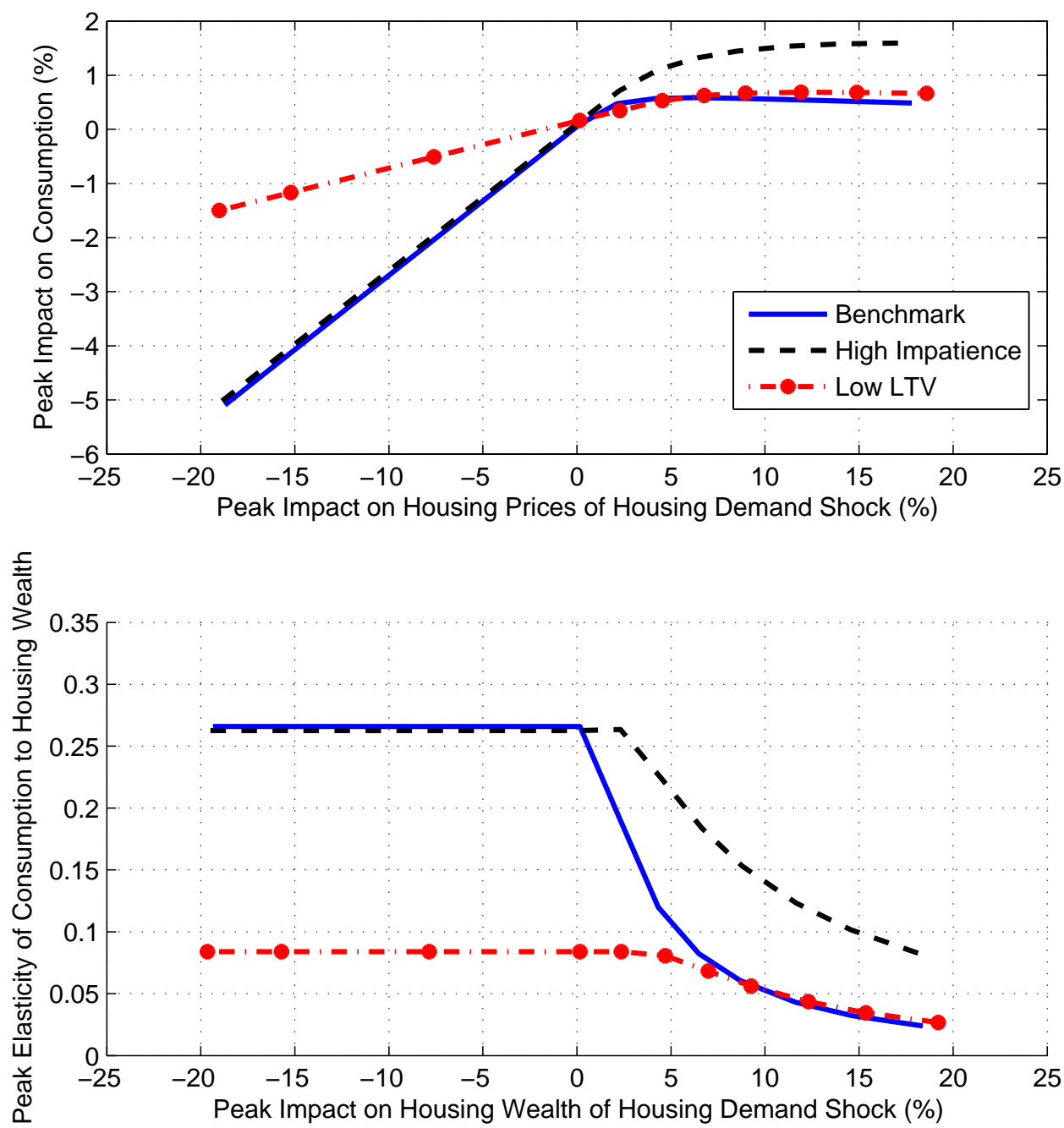

Note: The top panel plots the maximum response of consumption relative to the zero baseline following a housing price shock of size given by the x-axis, in the benchmark model (Benchmark), in a model with higher borrowers impatience, and in a model with a lower LTV Ratio. The bottom panel plots the maximum elasticity of consumption to housing wealth given a housing wealth shock of size given by the $\mathrm{x}$-axis. The housing price and wealth shocks are caused by a housing preference shock. 
Figure 7: Response of Consumption to Positive and Negative Changes in Housing Prices in the Full DSGE Model. Allowing for Zero Lower Bound
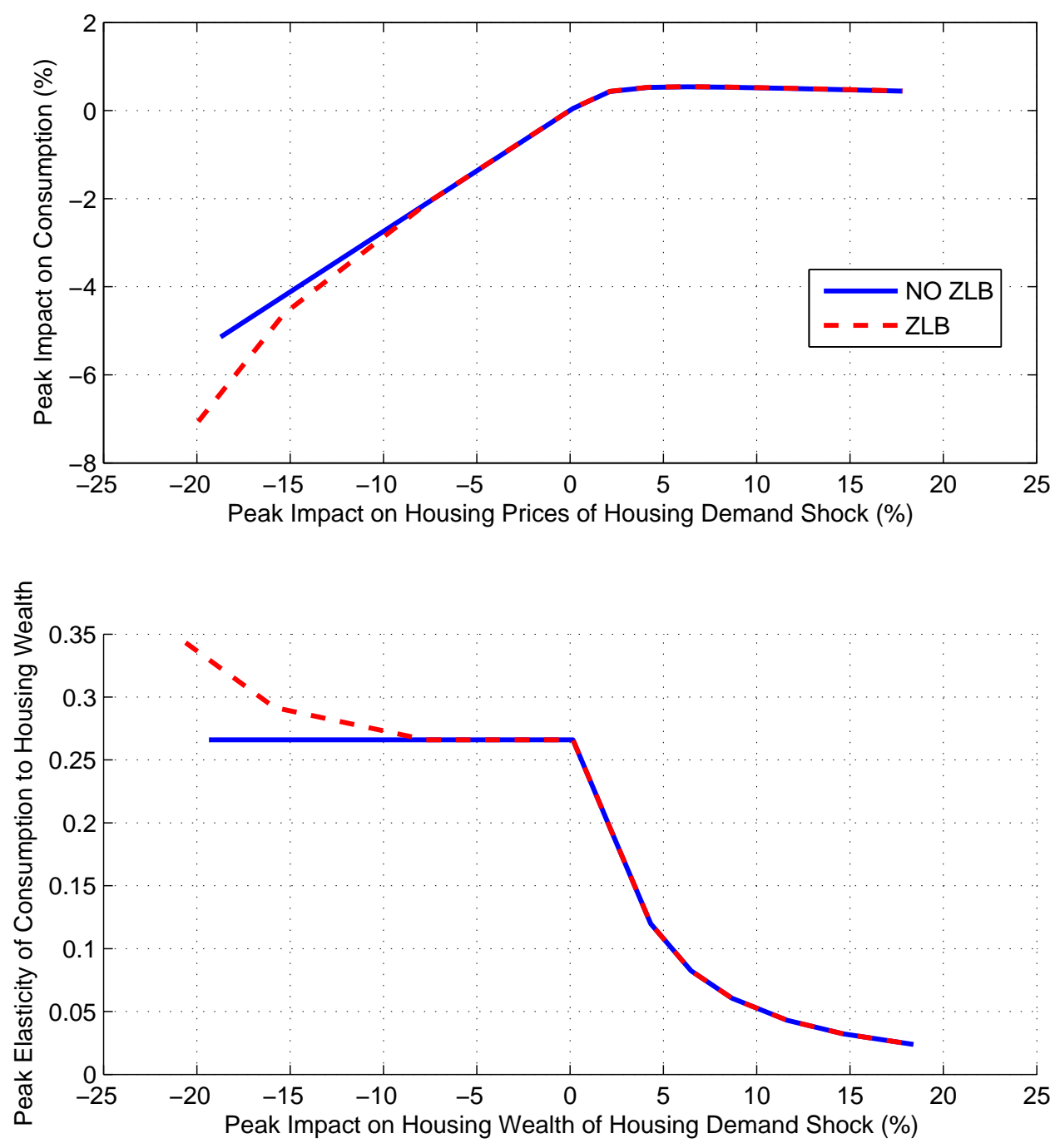

Note: The top panel plots the maximum response of consumption relative to the zero baseline following a housing price shock of size given by the $\mathrm{x}$-axis, in the model without zero lower bound on nominal interest rates (NO ZLB) and in a model with the zero lower bound constraint (ZLB). The bottom panel plots the maximum elasticity of consumption to housing wealth given a housing wealth shock of size given by the x-axis. The housing price and wealth shocks are caused by a housing preference shock. 
Figure 8: House Prices and Economic Activity by State
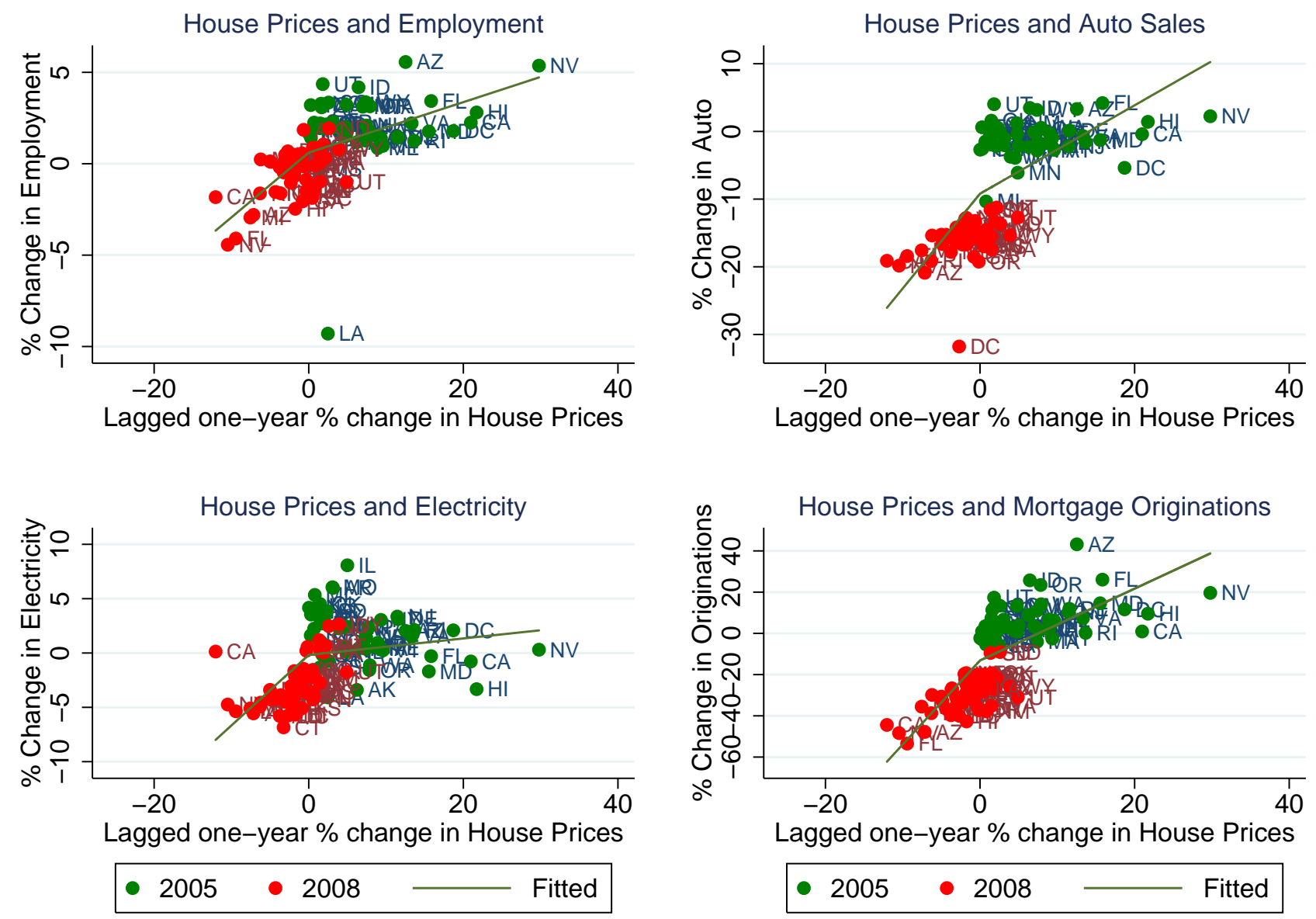

Note: Each panel shows house price growth and activity growth across US states in 2005 and 2008. The "fitted" line shows the fitted values of a regression of activity growth on house prices growth broken down into positive and negative changes. 
Figure 9: A Transfer from Lenders to Borrowers Against a Background of Low and High House Prices
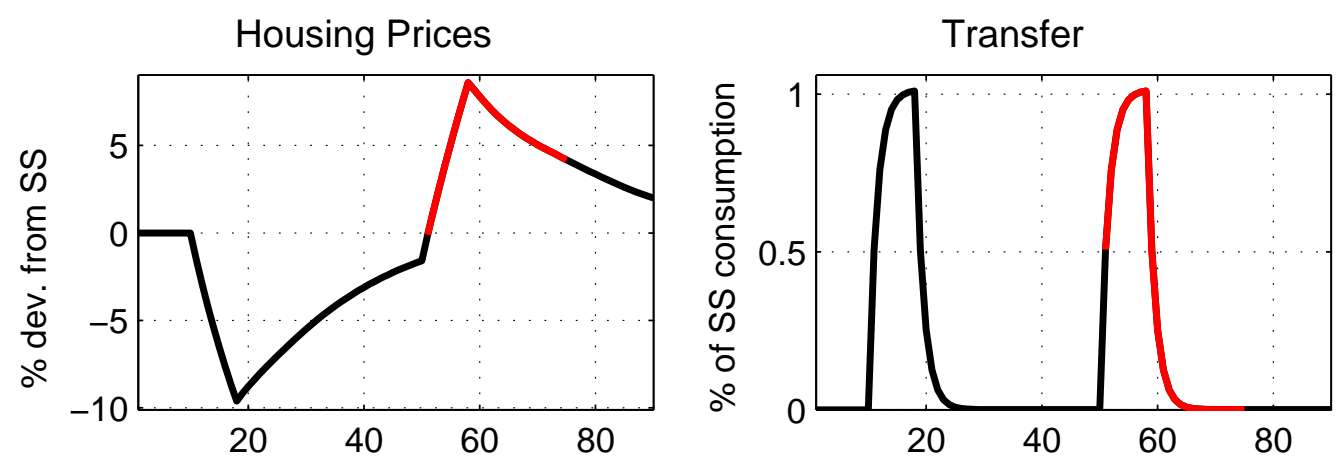

Consumption

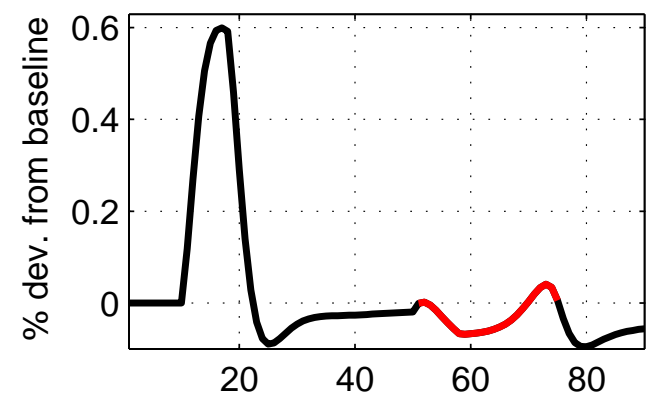

Hours
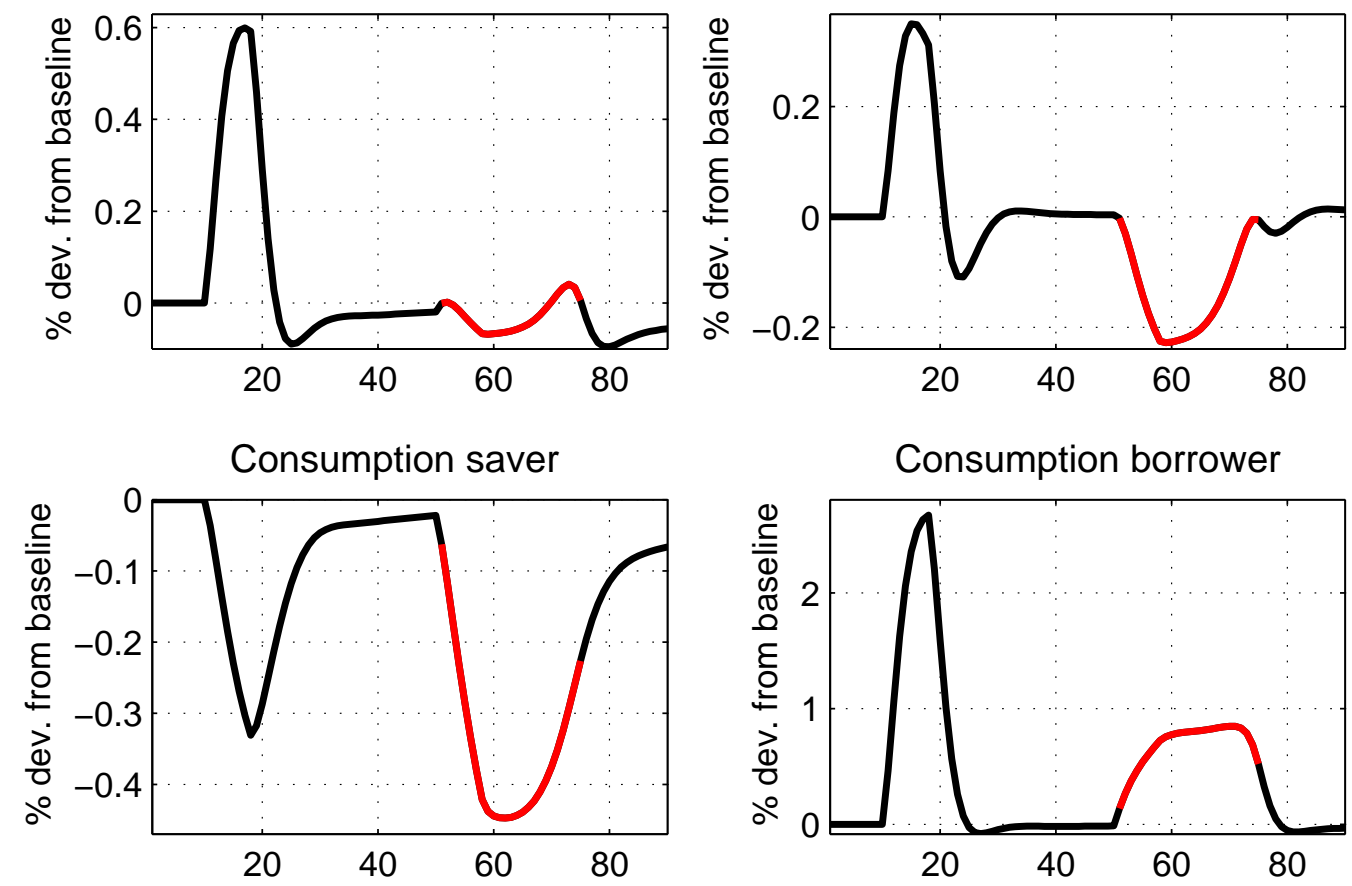

Note: The figure shows the effects of two unexpected lump-sum transfers from savers to borrowers each sized at 1 percent of steady-state total consumption. The first transfer (periods 10 to 19) happens against a baseline of low house prices and tight collateral constraints. The second transfer (periods 50 to 59) happens against a baseline of high house prices and slack collateral constraints. Both housing price changes in the baseline stem from a housing preference shock. The responses of consumption, hours, consumption of savers, and consumption of borrowers are shown in deviation from the baseline to isolate the partial effect of the transfer shocks. The variables are plotted in red when the collateral constraint is slack. 
Table 1: Parameter Values

\begin{tabular}{cccccc}
\hline \hline & Parameter & Value & & Parameter & Value \\
\hline$\varepsilon$ & habit saver & 0.32 & $\beta$ & discount saver & 0.9925 \\
$\varepsilon^{\prime}$ & habit borrower & 0.58 & $\overline{\mathrm{j}}$ & housing utility weight & 0.12 \\
$\eta$ & labor disutility saver & 0.52 & $\mu_{c}$ & capital share, goods & 0.35 \\
$\eta^{\prime}$ & labor disutility borrower & 0.51 & $\mu_{h}$ & capital share, housing & 0.1 \\
$\xi$ & labor substitutability saver & 0.66 & $\mu_{l}$ & land share, housing & 0.10 \\
$\xi^{\prime}$ & labor substitutability borrower & 0.97 & $\mu_{b}$ & intermediates share, housing & 0.10 \\
$\phi_{k, c}$ & adj.cost, capital for goods & 14.25 & $\delta_{h}$ & housing depreciation & 0.01 \\
$\phi_{k, h}$ & adj.cost, capital for housing & 10.90 & $\delta_{k c}$ & capital depreciation, goods & 0.025 \\
$\rho_{j}$ & AR(1) housing demand shock & 0.96 & $\delta_{k h}$ & capital depreciation, housing & 0.03 \\
$r_{\pi}$ & inflation response Taylor rule & 1.44 & $\bar{X}_{1}$ & price markup & 1.15 \\
$r_{Y}$ & output response Taylor rule & 0.52 & $\bar{X}_{w c}$ & wage markup, goods sector & 1.15 \\
$\theta_{p}$ & Calvo price stickiness & 0.83 & $\bar{X}_{w h}$ & wage markup, housing sector & 1.15 \\
$\iota_{\pi}$ & Calvo price indexation & 0.69 & & & \\
$\theta_{w, c}$ & Calvo wage stickiness goods & 0.79 & $\alpha$ & savers wage share & 0.60 \\
$\iota_{w, c}$ & Calvo wage index. goods & 0.08 & $\bar{m}$ & loan-to-value ratio & 0.925 \\
$\theta_{w, h}$ & Calvo wage stickiness housing & 0.91 & $r_{R}$ & inertia, Taylor rule & 0.70 \\
$\iota_{w, h}$ & Calvo wage index. housing & 0.40 & $\rho_{m}$ & AR(1), LTV shock & 0.975 \\
$\zeta$ & Capital Utilization convexity & 0.69 & & & \\
$\gamma_{A C}$ & goods technology trend & 0.0032 & $\beta^{\prime}$ & discount borrower & $0.988^{*}$ \\
$\gamma_{A H}$ & housing technology trend & 0.0008 & $\sigma_{j}$ & st.dev housing pref. shock & $0.0858^{*}$ \\
$\gamma_{A H}$ & investment technology trend & 0.0027 & $\sigma_{m}$ & st.dev LTV shock & $0.0220^{*}$ \\
\hline
\end{tabular}

Note: Parameters denoted with * are estimated in Section 4. 
Table 2: State-Level Regressions: Employment in Services and House Prices

\begin{tabular}{|c|c|c|c|c|c|}
\hline & \multicolumn{5}{|c|}{ \% Change in Employment $\left(\Delta e m p_{t}\right)$} \\
\hline$\Delta h p_{t-1}$ & $\begin{array}{c}\mathbf{0 . 1 4} \text { *** } \\
(0.01)\end{array}$ & & & & \\
\hline$\Delta h p_{-} h i g h_{t-1}$ & & $\begin{array}{c}\mathbf{0 . 0 7} \text { *** } \\
(0.01)\end{array}$ & $\begin{array}{c}\mathbf{0 . 0 8} \text { **** } \\
(0.01)\end{array}$ & $\begin{array}{l}\mathbf{0 . 0 3} * \\
(0.02)\end{array}$ & $\begin{array}{c}\mathbf{0 . 0 2} \\
(0.01)\end{array}$ \\
\hline$\Delta h p_{-}$low $_{t-1}$ & & $\begin{array}{c}\mathbf{0 . 2 4} * * * \\
(0.02)\end{array}$ & $\begin{array}{c}\mathbf{0 . 1 2} \text { **** } \\
(0.02)\end{array}$ & $\begin{array}{c}\mathbf{0 . 0 8} \boldsymbol{*} * * * \\
(0.02)\end{array}$ & $\begin{array}{c}\mathbf{0 . 0 7} * * * \\
(0.02)\end{array}$ \\
\hline$\Delta e m p_{t-1}$ & & & & $\begin{array}{c}\mathbf{0 . 2 6} \mathbf{6}^{* * *} \\
(0.08)\end{array}$ & $\begin{array}{c}\mathbf{0 . 2 3} \text { **** } \\
(0.09)\end{array}$ \\
\hline sincome $_{t-1}$ & & & & & $\begin{array}{c}\mathbf{0 . 0 7} * * \\
(0.03)\end{array}$ \\
\hline pval difference & & 0.000 & 0.100 & 0.013 & 0.017 \\
\hline Time effects & no & no & yes & yes & yes \\
\hline Observations & 1071 & 1071 & 1071 & 1020 & 1020 \\
\hline States & 51 & 51 & 51 & 51 & 51 \\
\hline R-squared & 0.12 & 0.16 & 0.66 & 0.72 & 0.73 \\
\hline
\end{tabular}

Note: Regressions using annual observations from 1991 to 2011 on 50 States and the District of Columbia. Robust standard errors in parenthesis. ${ }^{* * *}, * *, *$ : Coefficients statistically different from zero at 1, 5 and $10 \%$ confidence level, respectively. pval is the p-value of the test for difference between low-house price and high-house prices coefficient.

Data Sources and Definitions: $\Delta h p$ is the inflation-adjusted (using the GDP deflator) percent change in the FHFA House Price Index. $\Delta e m p$ is the percent change in employment in the Non-Tradable Service Sector which includes: Retail Trade, Transportation and Utilities, Information, Financial Activities, Professional and Business Services, Education and Health Services, Leisure and Hospitality, and Other Services (source: BLS Current Employment Statistics: Employment, Hours, and Earnings - State and Metro Area). Dincome is the percent change in the inflation-adjusted state-level disposable personal income (source: Bureau of Economic Analysis). 
Table 3: State-Level Regressions: Auto Sales and House Prices

\begin{tabular}{|c|c|c|c|c|c|}
\hline & \multicolumn{5}{|c|}{$\%$ Change in Auto Sales $\left(\Delta a u t o_{t}\right)$} \\
\hline$\Delta h p_{t-1}$ & $\begin{array}{c}\mathbf{0 . 2 4} * * * \\
(0.03)\end{array}$ & & & & \\
\hline$\Delta h p_{-} h i g h_{t-1}$ & & $\begin{array}{l}\mathbf{- 0 . 0 5} \\
(0.04)\end{array}$ & $\begin{array}{c}\mathbf{0 . 1 6} \text { *** } \\
(0.04)\end{array}$ & $\begin{array}{c}\mathbf{0 . 1 1} \text { *** } \\
(0.03)\end{array}$ & $\begin{array}{c}\mathbf{0 . 0 7} * * \\
(0.03)\end{array}$ \\
\hline$\Delta h p_{-} l o w_{t-1}$ & & $\begin{array}{c}\mathbf{0 . 6 2} \text { *** } \\
(0.05)\end{array}$ & $\begin{array}{c}\mathbf{0 . 3 3} * * * \\
(0.06)\end{array}$ & $\begin{array}{c}\mathbf{0 . 2 7} * * \\
(0.11)\end{array}$ & $\begin{array}{c}\mathbf{0 . 2 0} * * \\
(0.09)\end{array}$ \\
\hline$\Delta$ auto $_{t-1}$ & & & & $\begin{array}{c}\mathbf{0 . 2 3} \\
(0.17)\end{array}$ & $\begin{array}{c}\mathbf{0 . 2 1} \\
(0.17)\end{array}$ \\
\hline $\operatorname{sincome}_{t-1}$ & & & & & $\begin{array}{c}\mathbf{0 . 3 4} \mathbf{4}^{* * *} \\
(0.11)\end{array}$ \\
\hline pval difference & & 0.000 & 0.040 & 0.137 & 0.155 \\
\hline Time effects & no & no & yes & yes & yes \\
\hline Observations & 969 & 969 & 969 & 918 & 918 \\
\hline States & 51 & 51 & 51 & 51 & 51 \\
\hline R-squared & 0.02 & 0.06 & 0.86 & 0.87 & 0.88 \\
\hline
\end{tabular}

Note: State-level Regressions using annual observations from 1992 to 2011 on 50 States and the District of Columbia. Robust standard errors in parenthesis. $* * *, * * *$, Coefficients statistically different from zero at 1, 5 and $10 \%$ confidence level, respectively. pval is the p-value of the test for difference in the coefficients for low-house prices and high-house prices.

Data Sources and Definitions: $\Delta$ auto is the percent change in inflation-adjusted auto sales, "Retail Sales: Motor vehicle and parts dealers" from Moody's Analytics Database. Auto sales data are constructed with underlying data from the US Census Bureau and employment statistics from the BLS. The two Census Bureau surveys are the quinquennial Census of Retail Trade, a subset of the Economic Census, and the monthly Advance Retail Trade and Food Services Survey. See Table 2 for other variable definitions. 
Table 4: State-Level Regressions: Electricity Consumption and House Prices

\begin{tabular}{|c|c|c|c|c|c|}
\hline & \multicolumn{5}{|c|}{ "\% Change in Electricity Consumption $\left(\Delta e l e c_{t}\right)$} \\
\hline$\Delta h p_{t-1}$ & $\begin{array}{c}\mathbf{0 . 1 1} * * * \\
(0.02)\end{array}$ & & & & \\
\hline$\Delta h p_{-} h i g h_{t-1}$ & & $\begin{array}{c}\mathbf{0 . 0 3} \\
(0.02)\end{array}$ & $\begin{array}{c}\mathbf{0 . 0 9} * * * \\
(0.02)\end{array}$ & $\begin{array}{c}\mathbf{0 . 1 4} * * * \\
(0.03)\end{array}$ & $\begin{array}{c}\mathbf{0 . 1 2} \\
(0.03)\end{array}$ \\
\hline$\Delta h p \_l o w_{t-1}$ & & $\begin{array}{c}\mathbf{0 . 2 4} * * * \\
(0.03)\end{array}$ & $\begin{array}{c}\mathbf{0 . 1 6} * * * \\
(0.03)\end{array}$ & $\begin{array}{c}\mathbf{0 . 2 2} * * * \\
(0.04)\end{array}$ & $\begin{array}{c}\mathbf{0 . 1 9} * * * \\
(0.04)\end{array}$ \\
\hline$\Delta e l e c_{t-1}$ & & & & $\begin{array}{c}-\mathbf{0 . 4 1} * * * \\
(0.02)\end{array}$ & $\begin{array}{c}-\mathbf{0 . 4 1} * * * \\
(0.02)\end{array}$ \\
\hline$\Delta_{i n c o m e} t-1$ & & & & & $\begin{array}{c}\mathbf{0 . 1 5} * * * \\
(0.05)\end{array}$ \\
\hline pval difference & & 0.000 & 0.105 & 0.058 & 0.090 \\
\hline Time effects & no & no & yes & yes & yes \\
\hline Weather Controls* & yes & yes & yes & yes & yes \\
\hline Observations & 1071 & 1071 & 1071 & 1020 & 1020 \\
\hline States & 51 & 51 & 51 & 51 & 51 \\
\hline R-squared & 0.04 & 0.04 & 0.08 & 0.12 & 0.12 \\
\hline
\end{tabular}

Note: State-level Regressions using annual observations from 1990 to 2011 on 50 States and the District of Columbia. Robust standard errors in parenthesis. ***,**,*: Coefficients statistically different from zero at 1, 5 and $10 \%$ confidence level, respectively. pval is the p-value of the test for difference in the coefficients for low-house prices and high-house prices.

Data Sources and Definitions: $\Delta e l e c$ is the percent change in Residential Electricity Consumption (source: the U.S. Energy Information Administration's Electric Power Monthly publication. Electricity Power Annual: Retail Sales - Total Electric Industry - Residential Sales, NSA, Megawatt-hours). See Table 2 for other variable definitions. All regressions in the Table control separately for number of heating degree days and number of cooling degree days in each state (source: U.S. National Oceanic and Atmospheric Administration's National Climatic Data Center). 
Table 5: MSA Level: Employment in Services and House Prices

\begin{tabular}{|c|c|c|c|c|c|}
\hline & \multicolumn{5}{|c|}{$\%$ Change in Employment $\left(\Delta e m p_{t}\right)$} \\
\hline$\Delta h p_{t-1}$ & $\begin{array}{c}\mathbf{0 . 1 3 4} \text { *** } \\
(0.006)\end{array}$ & & & & \\
\hline$\Delta h p_{-} h i g h_{t-1}$ & & $\begin{array}{c}\mathbf{0 . 1 0 4} * * * \\
(0.008)\end{array}$ & $\begin{array}{c}\mathbf{0 . 0 5 8} \boldsymbol{*} * * * \\
(0.007)\end{array}$ & $\begin{array}{c}\mathbf{0 . 0 4 9} \\
(0.008 * *\end{array}$ & $\begin{array}{c}\mathbf{0 . 0 4 8} * * * \\
(0.008)\end{array}$ \\
\hline$\Delta h p \_l o w_{t-1}$ & & $\begin{array}{c}\mathbf{0 . 1 8 3} \boldsymbol{*} * * * \\
(0.009)\end{array}$ & $\begin{array}{c}\mathbf{0 . 0 9 9} * * * \\
(0.008)\end{array}$ & $\begin{array}{c}\mathbf{0 . 0 9 5} \text { *** } \\
(0.010)\end{array}$ & $\begin{array}{c}\mathbf{0 . 0 9 4} * * * \\
(0.010)\end{array}$ \\
\hline$\Delta e m p_{t-1}$ & & & & $\begin{array}{c}\mathbf{0 . 0 3 3} \\
(0.041)\end{array}$ & $\begin{array}{c}\mathbf{0 . 0 3 1} \\
(0.041)\end{array}$ \\
\hline sincome $_{t-1}$ & & & & & $\begin{array}{l}\mathbf{0 . 0 2 1} \text { * } \\
(0.011)\end{array}$ \\
\hline pval difference & & 0.0000 & 0.0003 & 0.0001 & 0.0000 \\
\hline Time effects & no & no & yes & yes & yes \\
\hline Observations & 5390 & 5390 & 5390 & 5147 & 5147 \\
\hline MSA & 262 & 262 & 262 & 262 & 262 \\
\hline R-squared & 0.09 & 0.10 & 0.37 & 0.39 & 0.39 \\
\hline
\end{tabular}

Note: MSA-level Regressions using annual observations from 1992 to 2011 on 262 MSAs (102 MSAs were dropped since they had incomplete or missing data on employment by sector). Robust standard errors in parenthesis. ${ }^{* * *}, * *, *$ : Coefficients statistically different from zero at 1, 5 and $10 \%$ confidence level, respectively. pval is the p-value of the test for difference in the coefficients for low-house prices and high-house prices.

Data Sources and Definitions: $\Delta$ income is the percent change in MSA-level inflation-adjusted personal income (source: BEA, Local and Metro Area Personal Income Release). For employment $(\Delta e m p)$ and house prices $(\Delta h p)$, see Table 2. 
Table 6: MSA Level: Auto Registrations and House Prices

\begin{tabular}{|c|c|c|c|c|}
\hline & \multicolumn{4}{|c|}{ Cross-sectional Regressions } \\
\hline & \multirow{2}{*}{\multicolumn{2}{|c|}{$\begin{array}{c}\text { Sample } \\
\text { 2002-2006 (Housing Boom) }\end{array}$}} & \multirow{2}{*}{\multicolumn{2}{|c|}{$\begin{array}{c}\text { Sample } \\
\text { 2006-2010 (Housing Bust) }\end{array}$}} \\
\hline & & & & \\
\hline & $\Delta h p$ & $\Delta c a r$ & $\Delta h p$ & $\Delta c a r$ \\
\hline Elasticity & $-7.26^{* * *}$ & & $4.69 * * *$ & \\
\hline & $(0.87)$ & & $(0.57)$ & \\
\hline$\Delta h p$ & & $\begin{array}{c}\mathbf{0 . 2 4} * * * \\
(0.06)\end{array}$ & & $\begin{array}{c}\mathbf{0 . 4 9 * * *} \\
(0.08)\end{array}$ \\
\hline Method & OLS & IV & OLS & IV \\
\hline Observations & 254 & 254 & 254 & 254 \\
\hline R-squared & 0.22 & 0.35 & 0.21 & 0.48 \\
\hline
\end{tabular}

Note: Regressions using Housing supply Elasticity at the MSA level as an instrument for house prices in a regression of MSA car registrations on MSA house prices. ***,**,*: Coefficients statistically different from zero at 1, 5 and $10 \%$ confidence level, respectively. The housing supply elasticity is taken from Saiz (2010) and measures limits on real-estate development due to geographic factors that affect the amount of developable land, as well as factors like zoning restrictions. The elasticity data are available for 269 cities: we dropped 15 areas because they were covering primary metropolitan statistical areas (PMSA), which are portions of metropolitan areas, rather than complete MSAs.

Data Sources: Car Registrations are retail (total less rental, commercial and government) auto registrations from Polk Automotive Data. $\Delta$ car is the percent change in car registrations. See Table 2 for other data sources. 


\section{References}

Abdallah, C. S. and W. D. Lastrapes (2012). Home equity lending and retail spending: Evidence from a natural experiment in texas. American Economic Journal: Macroeconomics 4 (4), 94-125. [3]

Adelino, M., A. Schoar, and F. Severino (2013). House prices, collateral and self-employment. Technical report, National Bureau of Economic Research. [23]

Barboza, D. (2011, October 20). China to allow some local governments to issue bonds. The New York Times. [23]

Bodenstein, M., L. Guerrieri, and C. Gust (2013). Oil shocks and the zero bound on nominal interest rates. Journal of International Money and Finance 32, 941-967. [12]

Campbell, J. and J. Cocco (2007). How do house prices affect consumption? evidence from micro data. Journal of Monetary Economics 54, 591-621. [3]

Case, K., J. Quigley, and R. Shiller (2005). Comparing wealth effects: The stock market versus the housing market. Advances in Macroeconomics 5(1), 1235-1235. [3, 4]

Case, K., J. Quigley, and R. Shiller (2011). Wealth effects revisited: 1978-2009. IBEN Working Paper W11-003. [4]

Chaney, T., D. Sraer, and D. Thesmar (2012). The collateral channel: How real estate shocks affect corporate investment. The American Economic Review 102(6), 2381-2409. [23]

Christiano, L., M. Eichenbaum, and S. Rebelo (2011). When is the government spending multiplier large? Journal of Political Economy 119(1), 78 - 121. [12, 17]

Christiano, L. J., M. Eichenbaum, and C. L. Evans (2005). Nominal rigidities and the dynamic effects of a shock to monetary policy. Journal of Political Economy 113(1), 1-45. [6]

Da, Z. and H. Yun (2010). Electricity consumption and asset prices. Available at SSRN 1608382. [20]

Del Negro, M. and C. Otrok (2007). 99 luftballons: Monetary policy and the house price boom across us states. Journal of Monetary Economics 54 (7), 1962-1985. [17]

Eggertsson, G. B. and M. Woodford (2003). The zero bound on interest rates and optimal monetary policy. Brookings Papers on Economic Activity 34(1), 139-235. [12]

Favara, G. and J. Imbs (2010). Credit supply and the price of housing. CEPR Discussion Papers 8129, C.E.P.R. Discussion Papers. [7]

Guerrieri, L. and M. Iacoviello (2013). Occbin: A toolkit for solving dynamic models with occasionally binding constraints. Manuscript, Federal Reserve Board. [44, 45]

Guerrieri, V. and G. Lorenzoni (2011). Credit crises, precautionary savings, and the liquidity trap. NBER Working Papers 17583, National Bureau of Economic Research, Inc. [7]

Hall, R. E. (2011). The long slump. American Economic Review 101, 431-469. [2]

Iacoviello, M. (2005). House prices, borrowing constraints, and monetary policy in the business cycle. American Economic Review 95(3), 739-764. [6]

Iacoviello, M. and S. Neri (2010). Housing market spillovers: Evidence from an estimated dsge model. American Economic Journal: Macroeconomics 2(2), 125-64. [2, 6, 7, 11] 
Jappelli, T. and L. Pistaferri (2010). The consumption response to income changes. Annual Review of Economics 2(1), 479-506. [4]

Jermann, U. and V. Quadrini (2012). Macroeconomic effects of financial shocks. American Economic Review 102(1), 238-71. [7]

Justiniano, A., G. E. Primiceri, and A. Tambalotti (2013, April). Household leveraging and deleveraging. NBER Working Papers 18941, National Bureau of Economic Research, Inc. [15]

Klapper, L., L. Laeven, and R. Rajan (2012). Trade credit contracts. Review of Financial Studies 25(3), 838-867. [23]

Liu, Z., P. Wang, and T. Zha (2013). Land-price dynamics and macroeconomic fluctuations. Econometrica 81(3), 1147-1184. [3, 7]

Lustig, H. and S. van Nieuwerburgh (2010). How much does household collateral constrain regional risk sharing? Review of Economic Dynamics 13(2), 265 - 294. [4]

Mian, A. and A. Sufi (2010). Household leverage and the recession of 2007-2009. IMF Economic Review 58, 74-117. [2]

Mian, A. and A. Sufi (2011). House prices, home equity-based borrowing, and the us household leverage crisis. American Economic Review 101(5), 2132-56. [3, 21]

Mian, A. R., K. Rao, and A. Sufi (2012). Household balance sheets, consumption, and the economic slump. Mimeo, Princeton University. [3, 21]

Midrigan, V. and T. Philippon (2011). Household leverage and the recession. NBER working paper no. 16965. [3]

Saiz, A. (2010). The geographic determinants of housing supply. The Quarterly Journal of Economics 125(3), 1253-1296. [21, 38]

Shiller, R. J. (2000). Irrational exuberance. Princeton University Press Princeton, N.J. ; Chichester. [7]

Smets, F. and R. Wouters (2007). Shocks and frictions in us business cycles: A bayesian dsge approach. American Economic Review 97(3), 586-606. [6, 10]

Soo, C. (2013). Quantifying animal spirits: news media and sentiment in the housing market. Technical report, Working paper, University of Pennsylvania. [7]

Tauchen, G. (1986). Finite state markov-chain approximations to univariate and vector autoregressions. Economics Letters 20(2), 177-181. [46]

Uhlig, H. (1995). A toolkit for analyzing nonlinear dynamic stochastic models easily. Technical report, Tilburg University, Center for Economic Research. [45] 


\section{Appendix}

\section{Appendix A Equilibrium Conditions of the Full Model}

We summarize here the equations describing the equilibrium of the full model. Let $u_{c}$ denote the marginal utility of consumption, $u_{n c}\left(u_{n h}\right)$ the marginal disutility of working in the goods (housing) sector, and $u_{h}$ the marginal utility of housing (with analogous definitions holding for impatient households). We denote with an upperbar the steady-state value of a particular variable. The budget constraint for patient households is:

$$
\begin{gathered}
c_{t}+\frac{k_{c, t}}{\mathrm{~A}_{k, t}}+k_{h, t}+k_{b, t}+q_{t} h_{t}+p_{l, t} l_{t}-b_{t}=\frac{w_{c, t}}{X_{w c, t}} n_{c, t}+\frac{w_{h, t}}{X_{w h, t}} n_{h, t}-\phi_{t} \\
+\left(R_{c, t} z_{c, t}+\frac{1-\delta_{k c}}{\mathrm{~A}_{k, t}}\right) k_{c, t-1}+\left(R_{h, t} z_{h, t}+1-\delta_{k h}\right) k_{h, t-1}+p_{b, t} k_{b, t}-\frac{R_{t-1} b_{t-1}}{\pi_{t}} \\
+\left(p_{l, t}+R_{l, t}\right) l_{t-1}+q_{t}\left(1-\delta_{h}\right) h_{t-1}+\operatorname{Div}_{t}-\frac{a\left(z_{c, t}\right)}{\mathrm{A}_{k, t}} k_{c, t-1}-a\left(z_{h, t}\right) k_{h, t-1} .
\end{gathered}
$$

The first-order conditions for patient households are:

$$
\begin{gathered}
u_{c, t} q_{t}=u_{h, t}+\beta G_{C} E_{t}\left(u_{c, t+1} q_{t+1}\left(1-\delta_{h}\right)\right) \\
u_{c, t}=\beta G_{C} E_{t}\left(u_{c, t+1} R_{t} / \pi_{t+1}\right) \\
u_{c, t}\left(\frac{1}{\mathrm{~A}_{k, t}}+\frac{\partial \phi_{c, t}}{\partial k_{c, t}}\right)=\beta G_{C} E_{t} u_{c, t+1}\left(R_{c, t+1} z_{c, t+1}-\frac{a\left(z_{c, t+1}\right)+1-\delta_{k c}}{\mathrm{~A}_{k, t+1}}-\frac{\partial \phi_{c, t+1}}{\partial k_{c, t}}\right) \\
u_{c, t}\left(1+\frac{\partial \phi_{h, t}}{\partial k_{h, t}}\right)=\beta G_{C} E_{t} u_{c, t+1}\left(R_{h, t+1} z_{h, t+1}-a\left(z_{h, t+1}\right)+1-\delta_{k h}-\frac{\partial \phi_{h, t+1}}{\partial k_{h, t}}\right) \\
u_{c, t} w_{c, t}=u_{n c, t} X_{w c, t} \\
u_{c, t} w_{h, t}=u_{n h, t} X_{w h, t} \\
u_{c t}\left(p_{b t}-1\right)=0 \\
R_{c t} \mathrm{~A}_{k t}=a^{\prime}\left(z_{c t}\right) \\
R_{h t}=a^{\prime}\left(z_{h t}\right) \\
\beta G_{C} E_{t} u_{c, t+1}\left(p_{l, t+1}+R_{l, t+1}\right) .
\end{gathered}
$$

The budget and borrowing constraint for impatient households are:

$$
\begin{gathered}
c_{t}^{\prime}+q_{t} h_{t}^{\prime}=\frac{w_{c, t}^{\prime}}{X_{w c, t}^{\prime}} n_{c, t}^{\prime}+\frac{w_{h, t}^{\prime}}{X_{w h, t}^{\prime}} n_{h, t}^{\prime}+b_{t}^{\prime}-\frac{R_{t-1}}{\pi_{t}} b_{t-1}^{\prime}+q_{t}\left(1-\delta_{h}\right) h_{t-1}^{\prime}+D i v_{t}^{\prime} \\
b_{t}^{\prime} \leq \mathrm{m}_{t} E_{t}\left(\frac{q_{t+1} h_{t}^{\prime} \pi_{t+1}}{R_{t}}\right)
\end{gathered}
$$


and the first-order conditions are:

$$
\begin{gathered}
u_{c^{\prime}, t} q_{t}=u_{h^{\prime}, t}+\beta^{\prime} G_{C} E_{t}\left(u_{c^{\prime}, t+1}\left(q_{t+1}\left(1-\delta_{h}\right)\right)\right)+E_{t}\left(\lambda_{t} \frac{m q_{t+1} \pi_{t+1}}{R_{t}}\right) \\
u_{c^{\prime}, t}=\beta^{\prime} G_{C} E_{t}\left(u_{c^{\prime}, t+1} \frac{R_{t}}{\pi_{t+1}}\right)+\lambda_{t} \\
u_{c^{\prime}, t} w_{c, t}^{\prime}=u_{n c^{\prime}, t} X_{w c, t}^{\prime} \\
u_{c^{\prime}, t} w_{h, t}^{\prime}=u_{n h^{\prime}, t} X_{w h, t}^{\prime}
\end{gathered}
$$

where $\lambda_{t}$ denotes the multiplier on the borrowing constraint, which is greater than zero in a neighborhood of the equilibrium.

The production technologies are:

$$
\begin{gathered}
Y_{t}=\left(\mathrm{A}_{c, t}\left(n_{c, t}^{\alpha} n_{c, t}^{\prime 1-\alpha}\right)\right)^{1-\mu_{c}}\left(z_{c, t} k_{c, t-1}\right)^{\mu_{c}} \\
I H_{t}=\left(\mathrm{A}_{h, t}\left(n_{h, t}^{\alpha} n_{h, t}^{\prime 1-\alpha}\right)\right)^{1-\mu_{h}-\mu_{l}-\mu_{b}} k_{b, t}^{\mu_{b}}\left(z_{h, t} k_{h, t-1}\right)^{\mu_{h}} l_{t-1}^{\mu_{l}} .
\end{gathered}
$$

The first-order conditions for the wholesale goods firms are:

$$
\begin{gathered}
\left(1-\mu_{c}\right) \alpha Y_{t}=X_{t} w_{c, t} n_{c, t} \\
\left(1-\mu_{c}\right)(1-\alpha) Y_{t}=X_{t} w_{c, t}^{\prime} n_{c, t}^{\prime} \\
\left(1-\mu_{h}-\mu_{l}-\mu_{b}\right) \alpha q_{t} I H_{t}=w_{h, t} n_{h, t} \\
\left(1-\mu_{h}-\mu_{l}-\mu_{b}\right)(1-\alpha) q_{t} I H_{t}=w_{h, t}^{\prime} n_{h, t}^{\prime} \\
\mu_{c} Y_{t}=X_{t} R_{c, t} z_{c, t} k_{c, t-1} \\
\mu_{h} q_{t} I H_{t}=R_{h, t} z_{h, t} k_{h, t-1} \\
\mu_{l} q_{t} I H_{t}=R_{l, t} l_{t-1} \\
\mu_{b} q_{t} I H_{t}=p_{b, t} k_{b, t} .
\end{gathered}
$$

The price Phillips curve is:

$$
\log \pi_{t}-\iota_{\pi} \log \pi_{t-1}=\beta G_{C}\left(E_{t} \log \pi_{t+1}-\iota_{\pi} \log \pi_{t}\right)-\varepsilon_{\pi} \log \left(X_{t} / \bar{X}\right) .
$$

Denote with $\omega_{i, t}$ nominal wage inflation, that is, $\omega_{i, t}=\frac{w_{i, t} \pi_{t}}{w_{i, t-1}}$ for each sector/household pair. The four wage equations are:

$$
\begin{aligned}
\log \omega_{c, t}-\iota_{w c} \log \pi_{t-1} & =\beta G_{C}\left(E_{t} \log \omega_{c, t+1}-\iota_{w c} \log \pi_{t}\right)-\varepsilon_{w c} \log \left(X_{w c, t} / X_{w c}\right) \\
\log \omega_{c, t}^{\prime}-\iota_{w c} \log \pi_{t-1} & =\beta^{\prime} G_{C}\left(E_{t} \log \omega_{c, t+1}^{\prime}-\iota_{w c} \log \pi_{t}\right)-\varepsilon_{w c}^{\prime} \log \left(X_{w c, t} / X_{w c}\right) \\
\log \omega_{h, t}-\iota_{w h} \log \pi_{t-1} & =\beta G_{C}\left(E_{t} \log \omega_{h, t+1}-\iota_{w h} \log \pi_{t}\right)-\varepsilon_{w h} \log \left(X_{w h, t} / X_{w h}\right) \\
\log \omega_{h, t}^{\prime}-\iota_{w h} \log \pi_{t-1} & =\beta^{\prime} G_{C}\left(E_{t} \log \omega_{h, t+1}^{\prime}-\iota_{w h} \log \pi_{t}\right)-\varepsilon_{w h}^{\prime} \log \left(X_{w h, t} / X_{w h}\right)
\end{aligned}
$$

where $\varepsilon_{w c}=\left(1-\theta_{w c}\right)\left(1-\beta G_{C} \theta_{w c}\right) / \theta_{w c}, \varepsilon_{w c}^{\prime}=\left(1-\theta_{w c}\right)\left(1-\beta^{\prime} G_{C} \theta_{w c}\right) / \theta_{w c}$

$$
\varepsilon_{w h}=\left(1-\theta_{w c}\right)\left(1-\beta G_{C} \theta_{w c}\right) / \theta_{w c} \text { and } \varepsilon_{w h}^{\prime}=\left(1-\theta_{w h}\right)\left(1-\beta^{\prime} G_{C} \theta_{w h}\right) / \theta_{w h} \text {. }
$$


The Taylor rule is:

$$
R_{t}=\max \left(1,\left(R_{t-1}\right)^{r_{R}} \pi_{t}^{r_{\pi}\left(1-r_{R}\right)}\left(\frac{G D P_{t}}{G_{C} G D P_{t-1}}\right)^{r_{Y}\left(1-r_{R}\right)} \overline{r r}^{1-r_{R}}\right)
$$

where $G D P_{t}$ is the sum of the value added of the two sectors, that is $G D P_{t}=Y_{t}-k_{b, t}+\bar{q} I H_{t}$. Two market-clearing conditions are

$$
\begin{aligned}
& C_{t}+I K_{c, t} / \mathrm{A}_{k, t}+I K_{h, t}+k_{b, t}=Y_{t}-\phi_{t} \\
& h_{t}+h_{t}^{\prime}-\left(1-\delta_{h}\right)\left(h_{t-1}+h_{t-1}^{\prime}\right)=I H_{t} .
\end{aligned}
$$

By Walras' law, $b_{t}+b_{t}^{\prime}=0$. Finally, total land is normalized to unity:

$$
l_{t}=1
$$

The stochastic processes for the housing preference and for the loan-to-value ratio are given by:

$$
\begin{aligned}
\log \dot{j}_{t} & =\left(1-\rho_{j}\right) \log \overline{\mathbf{j}}+\rho_{j} \log \mathbf{j}_{t-1}+u_{j, t} \\
\log \mathrm{m}_{t} & =\left(1-\rho_{m}\right) \log \overline{\mathrm{m}}+\rho_{m} \log \mathrm{m}_{t-1}+u_{m, t} .
\end{aligned}
$$

In equilibrium, dividends paid to households equal respectively:

$$
\begin{gathered}
\operatorname{Div}_{t}=\frac{X_{t}-1}{X_{t}} Y_{t}+\frac{X_{w c, t}-1}{X_{w c, t}} w_{c, t} n_{c, t}+\frac{X_{w h, t}-1}{X_{w h, t}} w_{h, t} n_{h, t} \\
\operatorname{Div}_{t}^{\prime}=\frac{X_{w c, t}^{\prime}-1}{X_{w c, t}^{\prime}} w_{c, t}^{\prime} n_{c, t}^{\prime}+\frac{X_{w h, t}^{\prime}-1}{X_{w h, t}^{\prime}} w_{h, t}^{\prime} n_{h, t}^{\prime} .
\end{gathered}
$$

In addition, the functional forms for the capital adjustment cost and the utilization rate are:

$$
\begin{gathered}
\phi_{t}=\frac{\phi_{k c}}{2 G_{I K_{c}}}\left(\frac{k_{c, t}}{k_{c, t-1}}-G_{I K_{c}}\right)^{2} \frac{k_{c, t-1}}{\left(1+\gamma_{A K}\right)^{t}}+\frac{\phi_{k h}}{2 G_{I K_{h}}}\left(\frac{k_{h, t}}{k_{h, t-1}}-G_{I K_{h}}\right)^{2} k_{h, t-1} \\
a\left(z_{c, t}\right)=R_{c}\left(\varpi z_{c, t}^{2} / 2+(1-\varpi) z_{c, t}+(\varpi / 2-1)\right) \\
a\left(z_{h, t}\right)=R_{h}\left(\varpi z_{h, t}^{2} / 2+(1-\varpi) z_{h, t}+(\varpi / 2-1)\right)
\end{gathered}
$$

where $R_{c}$ and $R_{h}$ are the steady-state values of the rental rates of the two types of capital. In the estimation of the model, we specify our prior for the curvature of the capacity utilization function in terms of $\zeta=\varpi /(1+\varpi)$. With this change of variables, $\zeta$ is bounded between 0 and 1 , since $\varpi$ is positive.

The processes for technology are given by:

$$
\begin{aligned}
& \log \mathrm{A}_{c, t}=t \log \left(1+\gamma_{A C}\right) \\
& \log \mathrm{A}_{h, t}=t \log \left(1+\gamma_{A H}\right) \\
& \log \mathrm{A}_{k, t}=t \log \left(1+\gamma_{A K}\right)
\end{aligned}
$$

These processes imply a balanced growth path along which the growth rates of the real 
variables are:

$$
\begin{gathered}
G_{C}=G_{I K_{h}}=G_{q \times I H}=1+\gamma_{A C}+\frac{\mu_{c}}{1-\mu_{c}} \gamma_{A K} \\
G_{I K_{c}}=1+\gamma_{A C}+\frac{1}{1-\mu_{c}} \gamma_{A K} \\
G_{I H}=1+\left(\mu_{h}+\mu_{b}\right) \gamma_{A C}+\frac{\mu_{c}\left(\mu_{h}+\mu_{b}\right)}{1-\mu_{c}} \gamma_{A K}+\left(1-\mu_{h}-\mu_{l}-\mu_{b}\right) \gamma_{A H} ; \\
G_{q}=1+\left(1-\mu_{h}-\mu_{b}\right) \gamma_{A C}+\frac{\mu_{c}\left(1-\mu_{h}-\mu_{b}\right)}{1-\mu_{c}} \gamma_{A K}-\left(1-\mu_{h}-\mu_{l}-\mu_{b}\right) \gamma_{A H} .
\end{gathered}
$$

Equations A.1 to A.38, together with the values for $I K_{c}, I K_{h}, G D P_{t}, \phi_{t}, a(z), D i v_{t}$ and $D i v_{t}^{\prime}$ and the laws of motion for the exogenous shocks, define a system of 38 equations in the following variables: $c, h, k_{c}, k_{h}, k_{b}, n_{c}, n_{h}, b, l, z_{c}, z_{h}, c^{\prime}, h^{\prime}, n_{c}^{\prime}, n_{h}^{\prime}, b^{\prime}, I H, Y, q, R, \pi, \lambda, X, w_{c}$, $w_{h}, w_{c}^{\prime}, w_{h}^{\prime}, X_{w c}, X_{w h}, X_{w c}^{\prime}, X_{w h}^{\prime}, R_{c}, R_{h}, R_{l}, p_{b}, p_{l}, \mathrm{j}$ and $\mathrm{m}$.

After detrending the variables by their balanced growth trends, we use the methods described in Appendix B and more fully developed in Guerrieri and Iacoviello (2013) to solve the model subject to the two occasionally binding constraints given by equations A.13 and A.33.

\section{Appendix B Solution Method for the Full Model}

We use a piecewise linear solution approach to find the equilibrium allocations for a given sequence of unforeseen shocks. This method resolves the problem of computing decision rules that approximate the equilibrium well both when the borrowing constraint binds and when it does not (similar reasoning applies to the nonnegativity constraint on the interest rate, as described at the end of this Section).

The economy features two regimes: a regime when collateral constraints bind; and a regime in which they do not, but are expected to bind in the future. ${ }^{22}$ With binding collateral constraints, the linearized system of necessary conditions for an equilibrium can be expressed as

$$
\mathcal{A}_{1} E_{t} X_{t+1}+\mathcal{A}_{0} X_{t}+\mathcal{A}_{-1} X_{t-1}+\mathcal{B} u_{t}=0
$$

where $\mathcal{A}_{1}, \mathcal{A}_{0}$, and $\mathcal{A}_{-1}$ are matrices of coefficients conformable with the vector $X$ collecting the model variables in deviation from the steady state for the regime with binding constraints; and where $u$ is the vector collecting all shock innovations (and $\mathcal{B}$ is the corresponding conformable matrix). Similarly, when the constraint is not binding, the linearized system can be expressed as

$$
\mathcal{A}_{1}^{*} E_{t} X_{t+1}+\mathcal{A}_{0}^{*} X_{t}+\mathcal{A}_{-1}^{*} X_{t-1}+\mathcal{B}^{*} u_{t}+\mathcal{C}^{*}=0
$$

where $\mathcal{C}^{*}$ is a vector of constants. When the constraint binds, we use standard linear solution

\footnotetext{
${ }^{22}$ If one assumes that the constraints are not expected to bind in the future, the regime with slack borrowing constraints becomes unstable, since borrowers' consumption falls over time and their debt rises over time until it reaches the debt limit, which contradicts the initial assumption.
} 
methods to express the decision rule for the model as

$$
X_{t}=\mathcal{P} X_{t-1}+\mathcal{Q} u_{t}
$$

When the collateral constraints do not bind, we use a guess-and-verify approach. We shoot back towards the initial conditions, from the first period when the constraints are guessed to bind again. For example, if the constraints do not bind in $t$ but are expected to bind the next period, the decision rule for period $t$ can be expressed, starting from B.2 and using the result that $E_{t} X_{t+1}=\mathcal{P} X_{t}$, as:

$$
X_{t}=-\left(\mathcal{A}_{1}^{*} \mathcal{P}+\mathcal{A}_{0}^{*}\right)^{-1}\left(\mathcal{A}_{-1}^{*} X_{t-1}+\mathcal{B}^{*} u_{t}+\mathcal{C}^{*}\right)
$$

We proceed in a similar fashion to compute the allocations for the case when collateral constraints are guessed not to bind for multiple periods or when they are foreseen to be slack starting in periods beyond $t$. As shown by equation B.4, the model dynamics when constraints are not binding depend both on the current regime (through the matrices $\mathcal{A}_{1}^{*}, \mathcal{A}_{0}^{*}$ and $\mathcal{A}_{-1}^{*}$ ) and on the expectations of future regimes when constraints will bind again (through the matrix $\mathcal{P}$, which is a nonlinear function of the matrices $\mathcal{A}_{1}, \mathcal{A}_{0}$ and $\left.\mathcal{A}_{-1}\right){ }^{23}$

It is tedious but straightforward to generalize the solution method described above for multiple occasionally binding constraints. ${ }^{24}$ The extension is needed to account for the zero lower bound (ZLB) on policy interest rates as well as the possibility of slack collateral constraints. In that case, there are four possible regimes: 1) collateral constraints bind and policy interest rates are above zero, 2) collateral constraints bind and policy interest rates are at zero, 3) collateral constraints do no bind and policy interest rates are above zero, 4) collateral constraints do not bind and policy interest rates are at zero. Apart from the proliferation of cases, the main ideas outlined above still apply.

\section{Appendix C Accuracy of Solution Method for the Full Model, tested using the Basic Model}

In the absence of an analytical solution for the models considered in this paper, we assess the solution algorithm used to solve the full general equilibrium model by comparing its performance against standard solution methods. As is well understood, standard global methods are subject to the curse of dimensionality, which renders such methods inoperable for our application. However, the partial equilibrium model of Section 2 of the paper can be solved with both our piecewise-linear algorithm, described in Appendix B, and with standard global solution methods. We use this smaller model to showcase the performance of our solution algorithm.

Among standard global methods, we focus on value function iteration since it is reliable,

\footnotetext{
${ }^{23}$ See for instance Uhlig (1995).

${ }^{24}$ For an array of models, Guerrieri and Iacoviello (2013) compare the performance of the piecewise perturbation solution described above against a dynamic programming solution obtained by discretizing the state space over a fine grid. Their results show that this solution method efficiently and quickly computes a solution that closely mimics the (perfect-foresight) nonlinear solution.
} 
accurate, and well understood. ${ }^{25}$ Overall, we find that key aspects of the global solution obtained through value function iteration are matched by the solution from the piecewise-linear algorithm. A key advantage of our algorithm is that it can handle the solution of a model, such as the one described in Section 3 of the paper, for which the curse of dimensionality renders standard global solution methods infeasible.

In Figures 10 and 11 we compare the simulated paths for house prices, consumption, leverage and debt using alternative solution methods. In Figure 10, we consider impulse responses to negative and positive house price shocks. In Figure 11, we generate a realization of house prices drawing shock innovations for 50 periods from the stochastic $\mathrm{AR}(1)$ process described in the text.

The "piecewise-linear" lines are computed using our method. The "nonlinear stochastic" lines refer to the nonlinear model solution obtained using global methods (value function iteration) under the assumption that the agents know and act upon the future distribution of the random shocks. The "nonlinear deterministic" lines refer to the perfect foresight case, solved using global methods under the assumption that agents ignore the future variance of shocks (that is, each period they expect that future shock innovations will equal zero with probability one). Finally, the "linear" lines refer to the model solved used brute force linearization under the - counterfactual - assumption that the borrowing constraint is always binding.

As can be seen from the figures, the nonlinear methods (value function iteration) and the piecewise linear method deliver very similar dynamics for the variables of interest. The similarity of the simulation paths causes the business cycle statistics (reported in Table 7) to be in broad agreement for those two methods. As expected, leverage and debt are on average lowest in the full stochastic case, since buffer stock motives - ignored by construction or by design in the other cases - cause agents to save more and reduce indebtedness. However, our method - which combines first-order perturbation solutions under two different regimes - comes remarkably close to matching the dynamics of the full nonlinear method under perfect foresight. As firstorder perturbation solutions ignore the possibility of future shocks, it is not surprising that our piecewise-linear method would not be able to capture precautionary motives present in the full stochastic non-linear solution. Accordingly, we consider the comparison with a perfectforesight non-linear solution as more apt. By contrast, the linearized solution that assumes that the constraint is always binding cannot capture the asymmetry of consumption and grossly overestimates its volatility.

As a further metric to judge to accuracy of our solution method, the last column of Table 7 reports the welfare cost for a household of using the approximated policy functions instead of the nearly-exact one (which we take to be the solution obtained via value function iteration) in order to solve the problem. The welfare cost of using the piecewise linear policy function is small (about $0.02 \%$ of lifetime consumption), and is one order of magnitude smaller than the cost of using the linearized policy function.

\footnotetext{
${ }^{25}$ Our state variables are the level of debt, the housing stock and the house price process. We discretize the AR(1) house price process with using Tauchen's method (Tauchen (1986)) with 101 grid points. We pick a solution range for housing and debt between -60 and +60 percent of their steady state values, discretized over 100 points for debt and 110 points for housing. In between iterations, we use Howard's improvement step. We verified that increasing the number of grid points did not materially change any of the results.
} 


\section{Appendix D Dynamic Responses to the Credit Shock in the Full Model}

Figure 12 plots the dynamic responses of house prices, consumption, hours, the multiplier on borrowing constraint, LTV and debt to two credit shocks equal to twice their estimated standard deviation. Starting in period 1, a negative credit shock, caused by a 4 percentage points persistent decline in the maximum loan-to-value (LTV) ratio (phased in over a two-year period), causes consumption to drop 0.8 percent, and house prices to drop about 0.15 percent at the trough relative to their unshocked path. In period 51, a positive credit shock, caused by a 4 percentage points persistent increase in the maximum LTV ratio, causes consumption to rise about 0.4 percent, and house prices to rise about 0.1 percent relative to their unshocked path. However, following the positive credit shock, house prices initially fall relative to the unshocked path, as the collateral constraint becomes temporarily slack.

\section{Appendix E State-Level Evidence on House Prices and Mortgage Originations}

Because the effects of low and high house prices on consumption work in our model through tightening or relaxing borrowing constraints, it is important to check whether measures of leverage also depend asymmetrically on house prices. Table 8 shows how mortgage originations at the state level respond to changes in house prices. We choose mortgage originations because they are available for a long time period, and because they are a better measure of the flow of new credit to households than the stock of existing debt. In all of the specifications in Table 8, mortgage originations depend asymmetrically on house prices, too. 
Figure 10: Accuracy of Solution Method: Impulse Responses
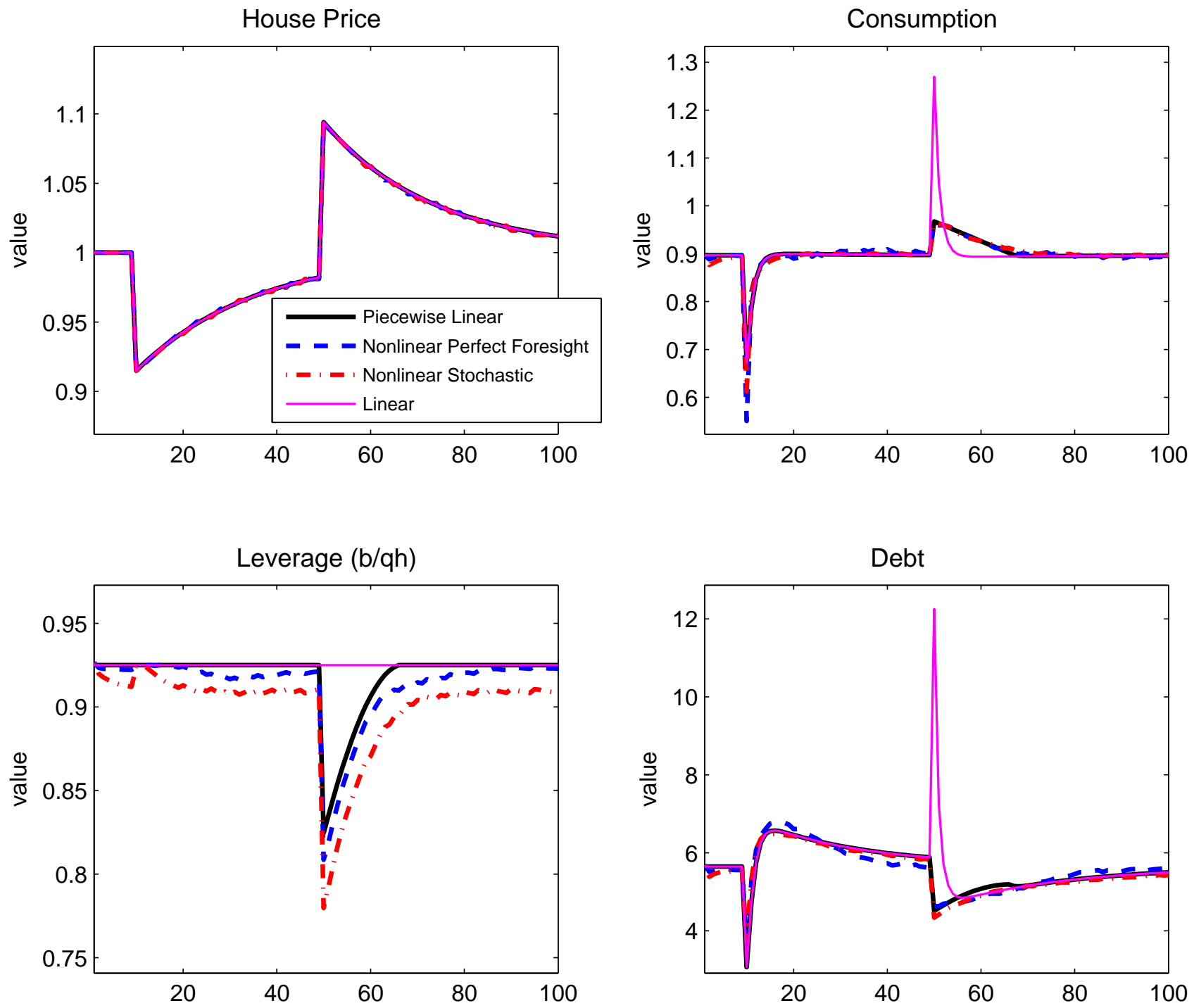

Note: Impulse Responses of the basic model to a negative house price shock in period 10 and a positive house price shock in period 50 . 
Figure 11: Accuracy of Solution Method: Simulated Time Series for the Basic Model
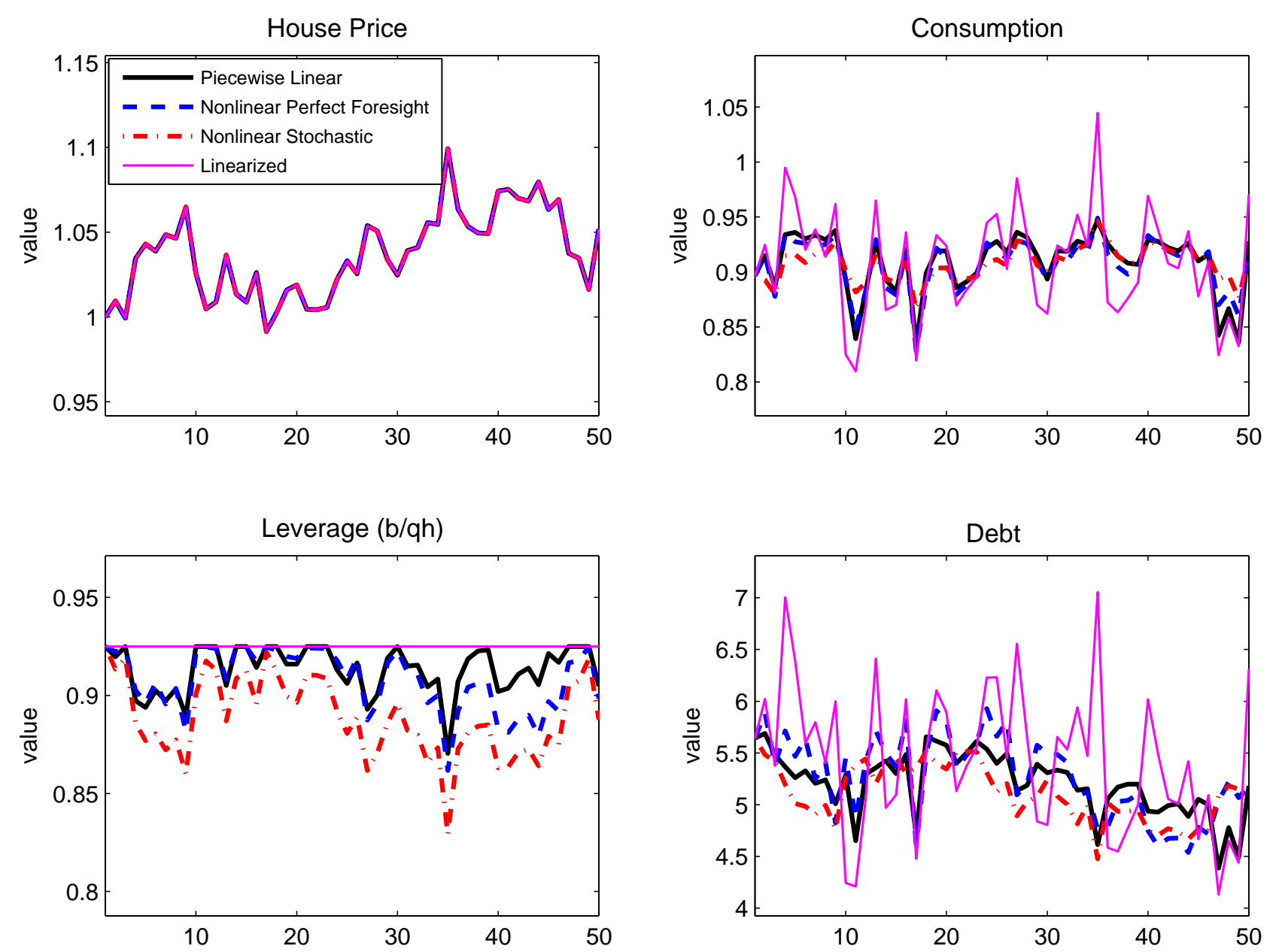

Note: Simulation of the basic model for 50 periods using identical realizations for the exogenous random shock to house prices. 
Figure 12: Impulse Responses to Negative and Positive Credit Shocks in the Full Model
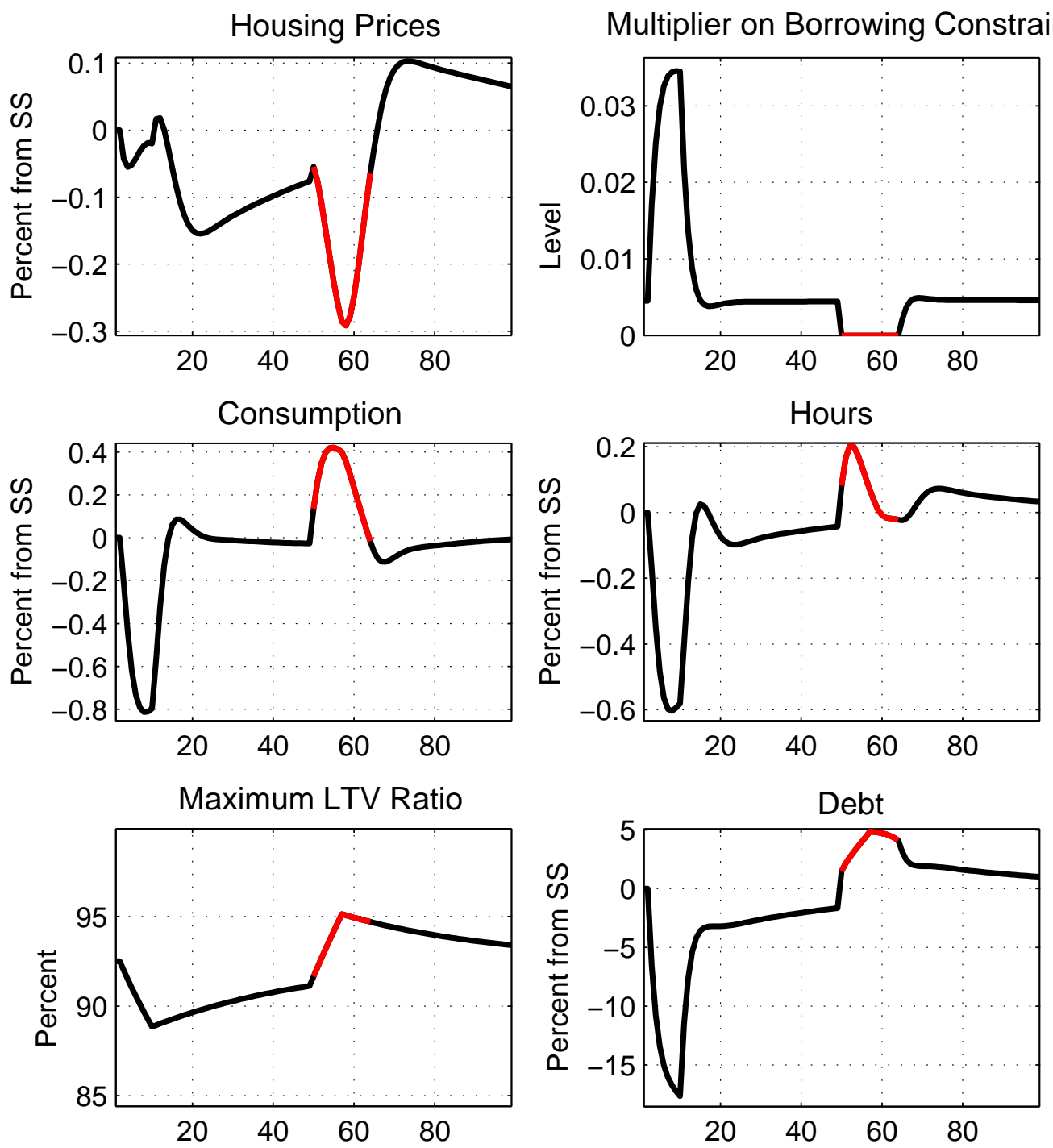

Note: Horizontal axis: horizon in quarters. The simulation shows the dynamic response of macroeconomic variables to two credit shocks. Starting in period 1, a series of negative credit shocks leads after one year to a decline in the maximum LTV ratio of 4 percentage points (2 standard deviations). In period 50, a series of positive credit shocks leads after four quarters to a 4 percentage points increase in the maximum LTV ratio. The variables are plotted in red when the collateral constraint is slack. 
Table 7: Accuracy of the Solution Method

\begin{tabular}{ccccccc}
\hline \hline Solution Method & \multicolumn{2}{c}{ Log Consumption } & \multicolumn{2}{c}{ Correlations } & $\frac{b}{q h}$ & $\Delta$ Welfare \\
& st.dev & skewness & $\log q, \log c$ & $\log q, \frac{b}{q h}$ & mean & \\
\hline Linear & $6.31 \%$ & -0.03 & 0.40 & 0.00 & 0.925 & $0.199 \%$ \\
Piecewise Linear & $4.55 \%$ & -1.27 & 0.55 & -0.61 & 0.908 & $0.022 \%$ \\
Nonlinear Perfect Foresight & $4.54 \%$ & -1.18 & 0.52 & -0.64 & 0.909 & $0.021 \%$ \\
Nonlinear Stochastic & $3.60 \%$ & -1.36 & 0.66 & -0.75 & 0.890 & - \\
\hline
\end{tabular}

Note: Selected properties of the basic model using different solution algorithms. These properties are based on the outcomes of a simulation of 5,000 observations using identical realizations for the exogenous random shocks.

The column labeled " $\Delta$ Welfare" indicates the annuity value of the transfer $\tau$ (as a percent of current consumption) that would make an agent using the solution method in the first column indifferent between using that method and using the Nonlinear Stochastic solution. Letting $\left(c_{t}^{*}, h_{t}^{*}\right)$ denote the consumption and housing policy in the nonlinear stochastic case, and $\left(\widetilde{c}_{t}, \widetilde{h}_{t}\right)$ the consumption policy in the linear case, the two associated value functions are respectively

$$
\begin{aligned}
W_{t}^{*} & =u\left(c_{t}^{*}, h_{t}^{*}\right)+\beta E_{t} W_{t+1}^{*} \\
\widetilde{W}_{t} & =u\left(\widetilde{c}_{t}, \widetilde{h}_{t}\right)+\beta E_{t} \widetilde{W}_{t+1} .
\end{aligned}
$$

The transfer $\tau$ is the solution to the following equation:

$$
\begin{gathered}
u\left(\widetilde{c}_{t}(1+\tau), \widetilde{h}\right)+\beta E_{t}\left(\widetilde{W}_{t+1}\right)= \\
\text { value of using suboptimal policy, after transfer }
\end{gathered}=\underset{\text { value of using optimal policy }}{W_{t}^{*}}
$$

By design, the nonlinear stochastic solution attains the highest level of welfare. Note that the linear and piecewise linear solution method could lead to spurious welfare reversals since they linearize the constraints of the original nonlinear problem thus transforming the original problem. To avoid this problem, we use these methods only to compute the borrowing and housing policy, and then obtain the consumption policy $c$ nonlinearly from the budget constraint. 
Table 8: State-Level Regressions: Mortgage Originations and House Prices

\begin{tabular}{|c|c|c|c|c|c|}
\hline & \multicolumn{5}{|c|}{$\%$ Change in Mortgage Originations $\left(\Delta\right.$ mori $\left._{t}\right)$} \\
\hline$\Delta h p_{t-1}$ & $\begin{array}{c}\mathbf{1 . 1 0} * * * \\
(0.18)\end{array}$ & & & & \\
\hline$\Delta h p_{-} h i g h_{t-1}$ & & $\begin{array}{c}-\mathbf{0 . 4 1} * \\
(0.24)\end{array}$ & $\begin{array}{c}1.08 * * * \\
(0.16)\end{array}$ & $\begin{array}{c}\mathbf{1 . 4 6}^{* * * *} \\
(0.21)\end{array}$ & $\begin{array}{c}\mathbf{1 . 5 4} \text { *** } \\
(0.33)\end{array}$ \\
\hline$\Delta h p_{-} l o w_{t-1}$ & & $\begin{array}{c}\mathbf{3 . 1 3} * * * \\
(0.59)\end{array}$ & $\begin{array}{c}1.85 * * * \\
(0.68)\end{array}$ & $\begin{array}{c}\mathbf{2 . 5 3} * * * \\
(0.90)\end{array}$ & $\begin{array}{c}2.67^{* *} \\
(1.11)\end{array}$ \\
\hline$\Delta m o r i_{t-1}$ & & & & $\begin{array}{c}-\mathbf{0 . 2 0} * * * \\
(0.02)\end{array}$ & $\begin{array}{c}-\mathbf{0 . 2 0} * * * \\
(0.02)\end{array}$ \\
\hline$\Delta$ income $_{t-1}$ & & & & & $\begin{array}{l}\mathbf{- 0 . 6 3} \\
(1.04)\end{array}$ \\
\hline pval difference & & 0.000 & 0.211 & 0.160 & 0.181 \\
\hline Time effects & no & no & yes & yes & yes \\
\hline Observations & 1020 & 1020 & 1020 & 969 & 969 \\
\hline States & 51 & 51 & 51 & 51 & 51 \\
\hline R-squared & 0.01 & 0.03 & 0.58 & 0.53 & 0.53 \\
\hline
\end{tabular}

Note: State-level Regressions using annual observations from 1992 to 2011 on 50 States and the District of Columbia. Robust standard errors in parenthesis. $* * * * * * *$ : Coefficients statistically different from zero at 1, 5 and $10 \%$ confidence level, respectively. pval is the p-value of the test for difference in the coefficients for low-house prices and high-house prices.

Data Sources and Definitions: $\Delta$ mori is the percent change in "Mortgage originations and purchases: Value" from the U.S. Federal Financial Institutions Examination Council: Home Mortgage Disclosure Act. See Table 2 for other variable definitions. 